\title{
EML1 (CNG-Modulin) Controls Light Sensitivity in Darkness and under Continuous Illumination in Zebrafish Retinal Cone Photoreceptors
}

\author{
Juan I. Korenbrot, ${ }^{1}$ Milap Mehta, ${ }^{2}$ Nomingerel Tserentsoodol,,${ }^{2}$ John H. Postlethwait, ${ }^{3}$ and Tatiana I. Rebrik ${ }^{2}$ \\ ${ }^{1}$ Departments of Ophthalmology and Physiology, School of Medicine, University of California, San Francisco, San Francisco, California $94143,{ }^{2}$ Albert Eye \\ Research Institute, Duke University Medical Center, Durham, North Carolina 27710, and ${ }^{3}$ Department of Biology, University of Oregon, Eugene, Oregon \\ 97403
}

The ligand sensitivity of cGMP-gated (CNG) ion channels in cone photoreceptors is modulated by CNG-modulin, a Ca ${ }^{2+}$-binding protein. We investigated the functional role of CNG-modulin in phototransduction in vivo in morpholino-mediated gene knockdown zebrafish. Through comparative genomic analysis, we identified the orthologue gene of CNG-modulin in zebrafish, emll, an ancient gene present in the genome of all vertebrates sequenced to date. We compare the photoresponses of wild-type cones with those of cones that do not express the EML1 protein. In the absence of EML1, dark-adapted cones are 5.3-fold more light sensitive than wild-type cones. Previous qualitative studies in several nonmammalian species have shown that immediately after the onset of continuous illumination, cones are less light sensitive than in darkness, but sensitivity then recovers over the following 15-20 s. We characterize light sensitivity recovery in continuously illuminated wild-type zebrafish cones and demonstrate that sensitivity recovery does not occur in the absence of EML1.

\section{Introduction}

The transduction signal in retinal cone photoreceptors is generated by light activation of an enzymatic cascade that lowers the outer segment (OS) cytoplasmic concentrations of both cGMP and $\mathrm{Ca}^{2+}$ which, in turn, control cGMP-gated (CNG) ion channels (for review, see Korenbrot, 2012a). The enzymatic cascade is tightly regulated to attain the light sensitivity and kinetics characteristic of the photosignal, as well as the capacity to adapt these parameters to the prevailing background light. Regulation arises, in part, from the feedback control by cytoplasmic $\mathrm{Ca}^{2+}$ of the activity of visual pigment kinase and guanylyl cyclase as well as the cGMP sensitivity of the CNG ion channels. This control is effected by specific $\mathrm{Ca}^{2+}$-binding proteins: recoverin for the kinase (Kawamura et al., 1996), guanylate cyclase activating protein for the cyclase (Dizhoor et al., 1994; Palczewski et al., 1994), and CNG-modulin for the CNG channels (Rebrik et al., 2012).

The cGMP dependence of CNG channel activity is described by cooperative binding with affinity constant KcGMP. The value of KcGMP decreases as $\mathrm{Ca}^{2+}$ concentration falls (Rebrik and Korenbrot, 1998) and the $\mathrm{Ca}^{2+}$ dependence of this modulation (Rebrik et al., 2000) overlaps the concentration range of light-

\footnotetext{
Received June 23, 2013; revised Sept. 29, 2013; accepted Sept. 30, 2013.

Author contributions: J.I.K. and T.I.R. designed research; J.I.K., M.M., N.T., and T.I.R. performed research; J.I.K., J.H.P., and T.I.R. analyzed data; J.I.K., J.H.P., and T.I.R. wrote the paper.

This work was supported in part by NIH Grants EY 05498 and EY020654 and Core Grant P30-EY005722, and a University of California Dickson Professorship award.

The authors declare no competing financial interests.

Correspondence should be addressed to Juan Korenbrot, Department of Ophthalmology, University of California, San Francisco, Box 0730, 10 Koret Way, San Francisco, CA 94143. E-mail: juan.korenbrot@ucsf.edu.

DOI:10.1523/JNEUROSCI.2659-13.2013

Copyright $\odot 2013$ the authors $\quad 0270-6474 / 13 / 3317763-14 \$ 15.00 / 0$
}

dependent changes in cone outer segment free $\mathrm{Ca}^{2+}$ (Sampath et al., 1999; Leung et al., 2007). Thus, in intact cone photoreceptors, the activity of CNG ion channels is simultaneously controlled by cGMP and $\mathrm{Ca}^{2+}$. The contribution of $\mathrm{Ca}^{2+}$-dependent $\mathrm{CNG}$ channel modulation to the cone photosignal has not been investigated previously, although a computational model suggests that in the absence of the modulation, cones can be expected to respond to light with increased sensitivity, lessened stability, and altered adaptation (Korenbrot, 2012b). We report studies of cone function in genetically modified zebrafish in which the expression of the CNG-modulin orthologue is suppressed, and demonstrate the functional role of the regulator protein in the control of cone absolute light sensitivity, both in the dark and under continuous illumination.

CNG-modulin was discovered in striped bass cone photoreceptors, but this species is not amenable to the application of genetic tools to control protein expression. Tools of experimental transgenesis are particularly well developed for application in zebrafish (Bill et al., 2009; Dahlem et al., 2012). To take advantage of these genetic tools, however, it is first necessary to identify the zebrafish gene orthologue of striped bass CNG-modulin. Orthologues are genes that evolved from a common ancestral gene and maintain similar structure. Identifying gene orthologues is a complex task, especially among fish, because two rounds of gene duplications, VGD1 and VGD2, occurred at about the time of the divergence of jawed and jawless vertebrates, and yet a third one occurred at the start of teleost fish radiation, teleost gene duplication (TGD) (Postlethwait et al., 1998; Dehal and Boore, 2005). Successful alignment of gene protein transcripts (Altschul et al., 1997) is a necessary, but not sufficient, criterion to identify gene orthologues, particularly among fish (Postlethwait, 2007). Truly, 
orthologous genes not only have well aligned protein transcripts, but their neighboring genes in the chromosome (synteny) are also conserved-analyses of chromosomal synteny are necessary to correctly identify gene orthologues (Catchen et al., 2009, 2011; Louis et al., 2013). We present a comparative genomic analysis that supports the identification in zebrafish of emll as the CNGmodulin orthologous gene.

\section{Materials and Methods}

Vertebrate animals. Research was conducted on zebrafish (Danio rerio). Animal upkeep and experimental protocols were approved by the Institutional Animal Care and Use Committees of the University of California, San Francisco and Duke University, and met all requirements of the NIH Office of Laboratory Animal Welfare and the Association for Assessment and Accreditation of Laboratory Animal Care International.

Bioinformatics. UniProtKB/Swiss-Prot is a thorough protein database containing manually annotated and reviewed records derived from the translation of published coding sequences. In this database, all protein sequences encoded by the same gene are merged into a single entry. It is available at http://www.uniprot.org. The continuous ensemble of available genomic structures was investigated with the genome Web browser available at http://www.ensembl.org. Chromosomal gene synteny derived from complete, annotated genomic sequences is available online at http://www.genomicus.biologie.ens.fr and http://syntenydb.uoregon. edu.

Generation morpholino-mediated gene-knockdown zebrafish. The antisense morpholino oligonucleotide covering -8 (UTR) +17 bp of the zebrafish eml1 gene (ENSDARG00000042840.7), 5' -GAGAAACCGTCC TCCATTCTCGTCC-3' (MO-EML1), was custom synthesized by GeneTools. The control morpholino (MO-control) oligomer was the standard designed by Gene-Tools, 5' -CCTCTTACCTCAGTTACAATTTATA-3' tagged with $3^{\prime}$ carboxyfluorescein.

One male and two female zebrafish were isolated and left to acclimate overnight. The next morning, the fish were allowed to mate, eggs were collected, and embryos were injected at the one- to four-cell stages. Approximately $2-3 \mathrm{nl}$ of morpholino solution in $\mathrm{ddH}_{2} \mathrm{O}(1 \mathrm{~mm})$ were injected using a PicoSpritzer III (Parker-Hannifin). Embryos were then collected in egg water and maintained at $28.5^{\circ} \mathrm{C}$ under $14 \mathrm{~h}$ light $/ 10 \mathrm{~h}$ dark cycles.

Immunohistochemistry. Zebrafish wild-type (wt) and morphant larvae were dark adapted for $1 \mathrm{~h}$, anesthetized in $0.2 \%$ tricaine, and immediately fixed in $2 \%$ paraformaldehyde in phosphate buffer, $\mathrm{pH} 7.4$, for $1 \mathrm{~h}$ at $4^{\circ} \mathrm{C}$. Each specimen was then equilibrated with 5\% sucrose/PBS for $1 \mathrm{~h}$ at room temperature and then with $30 \%$ sucrose/PBS overnight at $4^{\circ} \mathrm{C}$. It was then imbedded in OCT (Tissue-Tek) medium, frozen on dry ice, and stored at $-80^{\circ} \mathrm{C}$. Frozen sections $(12 \mu \mathrm{m}$ thick) were cut with a microtome (Microm HM550) at $-20^{\circ} \mathrm{C}$. Sections were incubated with $5 \%$ normal goat serum in PBS (0.1\% Triton X-100 in PBS, pH 7.4) for $1 \mathrm{~h}$ and then overnight with the primary CNG-modulin antibody (1:250; Rebrik et al., 2012) followed by incubation with a secondary anti-rabbit antibody $(2.5 \mu \mathrm{g} / \mathrm{ml})$ conjugated with the fluorescent dye Alexa 568 (Invitrogen) for $1 \mathrm{~h}$, and then in peanut agglutinin (PNA) conjugated with Alexa Fluor 488 (Invitrogen; 1:500) and $10 \mu \mathrm{g} / \mathrm{ml}$ Hoechst 33342 (Invitrogen) to label nuclei. Confocal images were acquired using a Nikon Eclipse $90 \mathrm{i}$ microscope and a C1 confocal scanner controlled by EZ-C1 version 3.80 software.

Western blots. Eyes were dissected from $6 \mathrm{~d}$ postfertilization (dpf) zebrafish larvae, both wild type and morphants, and homogenized in $0.1 \mathrm{ml}$ PBS containing 1\% Triton X-100 and protease inhibitor cocktail (Complete Ultra tablets, EDTA free; Roche Applied Science). After centrifugation to remove insoluble material, protein concentration was measured in the supernatant using a colorimetric assay (DC Protein Assay; BioRad). Proteins were separated by SDS-PAGE with $5 \mu \mathrm{g}$ of total protein wt and morphant samples loaded in side-by-side lanes. Proteins were blotted onto PVDF membrane and side-by-side wt and morphant lane pairs were reacted with a specific primary antibody, followed by a fluorescent secondary antibody (conjugated with Alexa Fluor 680). Images of the fluorescent bands were acquired with the Odyssey Infrared Imaging Sys- tem (LI-COR Biosciences). Images were analyzed using ImageJ software (NIH). For each wt and morphant image pair, a rectangular region of interest (ROI) was selected to include the entire wt fluorescent band and the mean $( \pm S D)$ gray level measured. The ROI was then displaced horizontally to overlap the morphant band, and its mean $( \pm S D)$ gray level was measured. To determine the difference in protein expression level between the two samples, the ratio of each sample's mean gray levels was calculated, and an error was estimated by computing the ratio covariance given each sample's variance (Bevington, 1969).

The primary antibodies used and their sources were as follows: zebrafish UV and blue opsin were generous gifts from Dr. D. Hyde (University of Notre Dame, Notre Dame, IN; Vihtelic et al., 1999), zebrafish cone arrestin was a generous gift from Dr. S. Neuhauss (University of Zurich, Zurich, Switzerland; Renninger et al., 2011), cone opsin kinase (GRK7) was a generous gift from Dr. E. Weiss (University of North Carolina, Chapel Hill, NC; Osawa et al., 2008), cone transducin $\alpha$ (G $\alpha \mathrm{tc}$ ) was a generous gift from Dr. E. Lobanova (Duke University, Durham, NC; Lobanova et al., 2010), the $\alpha$ subunit of the cone CNG ion channel (CNGA3) was from Abcam (catalog \#ab58716), and the $\beta$ subunit of the cone CNG ion channel (CNGB3) was from Santa Cruz Biotechnology (catalog \#sc-34991).

Electrical recording of the isolated cone mass receptor potential. Under dim red light, individual larvae were transferred into a $10 \% \mathrm{v} / \mathrm{v}$ HBSS containing $0.02 \%$ tricaine (or $0.002 \%$ for morphant larvae) and $500 \mu \mathrm{M}$ 1-(+)-2-amino-4-phosphonobutyric acid (L-AP4). As soon as its swimming motion stopped, the larva was transferred, dorsal side up, onto a small cylinder $(6 \times 3 \mathrm{~mm}$, diameter by height $)$ of polyvinyl alcohol (PVA) sponge immersed in the same solution. The sponge was removed from the solution, dried slightly by blotting, and placed in a smalldiameter $(6 \mathrm{~mm})$ cylindrical recording chamber constructed from acrylic plastic. The larva was immediately coated by gently brushing a gel of $3 \%$ methylcellulose in $10 \%$ HBSS over its full body length. This coat kept the larva wet and significantly prolonged the lifetime of electrical recordings. The chamber was then positioned within a light-shielded Faraday cage, and $100 \%$ oxygen gas streamed continuously over the larva. This prolonged animal survival because larvae respire through their skin. Animals were maintained in darkness for $10 \mathrm{~min}$ before commencing electrical recordings.

The reference electrode was either an $\mathrm{Ag} / \mathrm{AgCl}$ flat pellet placed underneath the PVA sponge or a $\%$ HBBS-agar bridge with an $\mathrm{Ag} / \mathrm{AgCl}$ pellet. The agar bridge was placed on the upper surface of the PVA sponge, $\sim 1$ $\mathrm{mm}$ from the larva. The active electrode was a glass microelectrode with a fire-polished $25 \mu \mathrm{m}$ tip produced from $1.5 \times 1.0 \mathrm{~mm}$ (outer diameter by inner diameter) capillary glass. The electrode was filled with HBSS, and a chlorinated Ag wire was placed within it. With a micromanipulator and under infrared video observation, the electrode tip was positioned at the midpoint between the nasal and caudal ends of the open eye, and gently pressed onto the dorsal limit of the cornea.

The voltage difference between the reference and active electrodes was recorded with a differential AC amplifier (Model 3000; A-M Systems) set to a bandpass between 0.1 and $300 \mathrm{~Hz}$, followed by an 8 pole Bessel filter set to bandpass DC to $300 \mathrm{~Hz}$ (Model 3342; Khron-Hite). Excess $60 \mathrm{~Hz}$ noise was removed digitally (Hum Bug; Quest Scientific). Analog data were digitized at $1 \mathrm{kHz}$ and acquired online on a PC (Digidata Model 1322A with pClamp10 software; Molecular Devices). The photovoltages measured in wild types were generally signal averaged (four to eight repeats), but they generally were not averaged when morphant larvae were studied because these animals are less robust, and only shorter recording times were possible. Mathematical functions were fit to experimental data by Levenberg-Marquardt least squares minimization (Origin 9.0; Origin Lab).

Photostimulation. The entire larva was illuminated by the collimated light output of a 2-mm-diameter liquid light guide positioned above it. Light was focused onto the other end of the light guide using one of two different optical benches. One bench used a xenon (Xe) light source (150 $\mathrm{W}$, ozone free) for flashes and a tungsten (W)-halide (250 W QTH) light source for steps. The two beams were combined with a cube beam splitter, and the emergent beam was focused onto the light guide. The spectral irradiance of both sources was selected between 380 and $800 \mathrm{~nm}$ using 

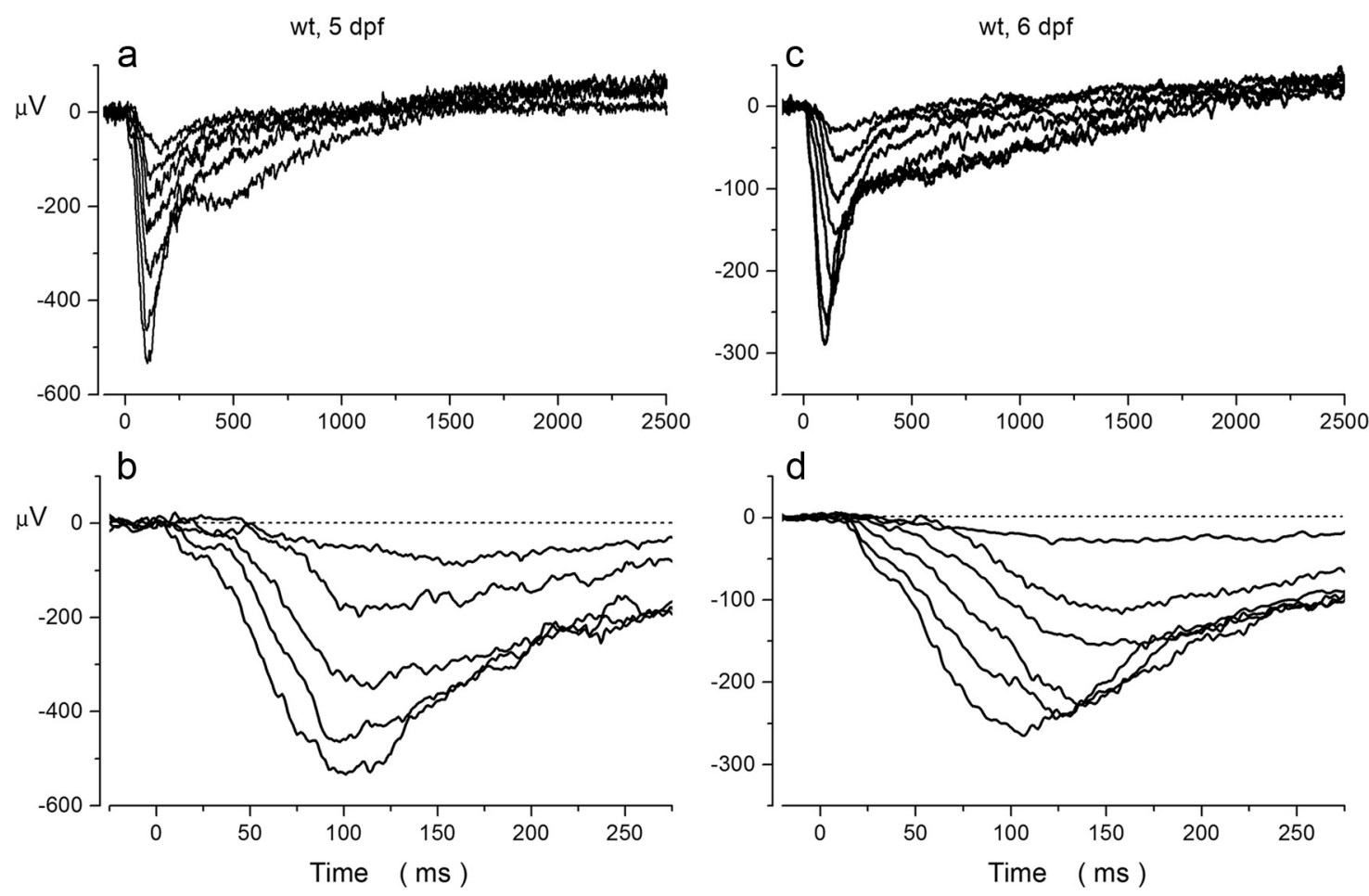

Figure 1. $\quad \boldsymbol{a}-\boldsymbol{d}, \mathrm{L}-\mathrm{AP} 4$ isolated cone mass receptor potential recorded at room temperature in dark-adapted $5 \mathrm{dpf}(\boldsymbol{a}, \boldsymbol{b})$ and $6 \mathrm{dpf}(\boldsymbol{c}, \boldsymbol{d})$ intact zebrafish larvae. $\boldsymbol{a}$, Responses elicited by $20 \mathrm{~ms}$ flashes of white light (LED source) of intensities $0.14,0.28,0.56,1.12,2.24,8.96$, and $19.92 \mathrm{~nJ} / \mathrm{mm}^{2} . \boldsymbol{b}$, Time-expanded view of the receptor potentials generated by the $0.14,0.56,2.24,4.48$, and $8.96 \mathrm{~nJ} / \mathrm{mm}^{2}$ stimuli.c, Responses elicited by $20 \mathrm{~ms}$ flashes of white light (LED source) of intensity $0.14,0.28,0.56,1.12,2.24,8.96,19.92$, and $39.84 \mathrm{~nJ} / \mathrm{mm}^{2}$.d, Time-expanded view of the receptor potentials generated by the $0.28,0.56,1.12,2.24,4.48$, and $8.96 \mathrm{~nJ} / \mathrm{mm}^{2}$ stimuli.

long- and short-pass optical filters (Schott; Corning). Light intensity was controlled with calibrated neutral density filters, and stimulus duration with electromechanical shutters (Uniblitz VS25; Vincent Associates). The second bench used a white LED as the light source of both steps and flashes (1 W SMD $6 \mathrm{~mm}$; Optek Technology). LED source intensity and stimulus duration were controlled with a programmable power supply commanded by the data acquisition software.

The irradiance spectrum (milliwatts per nanometer per square meter) of each "white" light source we used was different. The cool white LED spectrum has a principal component in the blue (narrow peak maximum, $\sim 450 \mathrm{~nm}$ ) and a second, broader, and less powerful component in the green (peak maximum, $\sim 550 \mathrm{~nm}$; www.optekinc.com). Xe and tungsten-halide irradiance have broad spectra that we narrowed to between 380 and $800 \mathrm{~nm}$. The short wavelength limit in this range of interest is determined by the long-pass optical filter in the photostimulator, whereas the long wavelength limit is determined by the long wavelength falloff of the absorbance spectrum of the "S" visual pigment expressed in blue-sensitive zebrafish cones (Cameron, 2002). Using the known irradiance spectrum of the light sources (www.newport.com), we computed the power flux densities (milliwatt per square meter) over the spectral range of interest. The unattenuated power flux densities of the sources was similar over the $380-500 \mathrm{~nm}$ spectral range: $\mathrm{Xe}=2115.8 \mathrm{~mW} / \mathrm{m}^{2}$, $\mathrm{W}$-halide $=2506 \mathrm{~mW} / \mathrm{m}^{2}$.

We emphasize that in the analysis of the experimental data presented here, results measured using one optical bench (Xe and W-halide) or the other (white LED) are never comingled or averaged together. The data that extensively characterize the cone mass receptor potential in wildtype larvae were generated with the Xe and W-halide bench. All data used to measure and compare side by side the cone receptor potential in morphant and wt larvae were generated exclusively with the LED optical bench.

\section{Results}

Zebrafish larvae are particularly advantageous subjects in studies of cone photoreceptor function because up to $10 \mathrm{dpf}$ cones are the only functional photoreceptors in the retina. Rod function is detectable only after 11-12 dpf (Branchek, 1984; Schmitt and Dowling, 1999; Bilotta et al., 2001). In the course of embryonic development, visual pigment gene expression identifies photoreceptor progenitor cells in the ventral zebrafish retina at $\sim 50 \mathrm{~h}$ after egg fertilization (Raymond et al., 1995; Schmitt et al., 1999; Takechi et al., 2003). However, morphogenic maturation (development of outer segments) and functional development lag behind differentiation by days. Light-responsive cone photoreceptors are first detected at $4 \mathrm{dpf}$ (Branchek, 1984; Saszik et al., 1999). UV-sensitive single cones are the earliest to mature, followed in a day or so by blue-sensitive single cones. Red- and green-sensitive double cones are not morphologically mature until 8-10 dpf (Robinson et al., 1995; Saszik et al., 1999; Schmitt et al., 1999). We limited our studies to larvae at 5 and $6 \mathrm{dpf}$, a time when the retina is pure cone in function, and UVand blue-sensitive single cones are the most abundant classes of functional cones.

\section{Isolation of the cone component in the zebrafish electroretinogram}

We measured the electrical photoresponse of cones in electroretinographic signals recorded across the intact eye of anesthetized zebrafish larvae. The cone mass receptor potential was isolated from other components of the ERG signal by incubating the larvae in L-AP4, an agonist of metabotropic glutamate receptor 6 (mGluR6; Wong et al., 2005; Nelson and Singla, 2009). In Figure 1 , we present a typical family of responses elicited by white light flashes of varying intensity in 5 and $6 \mathrm{dpf}$ zebrafish larvae. The rapid, cornea-negative signal is almost exclusively generated by the summed field potential generated by all cones, but it possibly includes a small contribution from a component named PIInm 


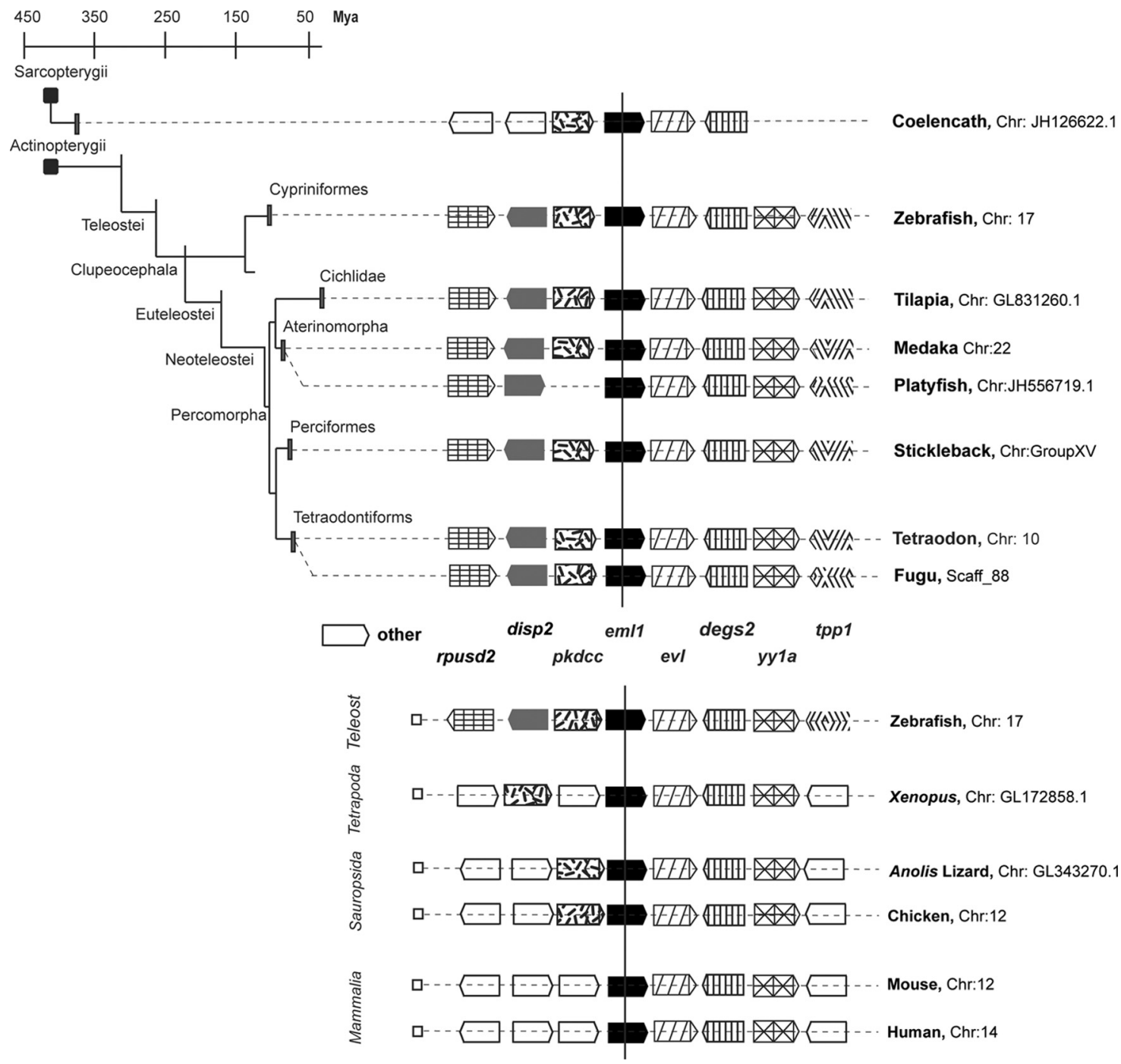

Figure 2. Schematic representation of synteny (neighboring genes) surrounding EML1 in the chromosome of fish and other selected vertebrates, as labeled. The representation does not reflect the actual physical distance between the genes, just their synteny. To address chromosomal inversion, an arrowhead is used to indicate the gene's transcription orientation (www.genomicus.com). Homologous genes have the same name in all species but, by convention, the text format varies with species. We use the zebrafish convention (lower case italics). The chromosome segment sketched is listed next to the species name. Fish phylogeny and approximate time calibration (millions of years ago) are redrawn from the study by Near et al. (2012). EML1 is found in all vertebrates, including fish, and its synteny is strongly conserved.

that originates in the activity of excitatory amino acid transporters (Nelson and Singla, 2009), as well as a component that originates in Muller cells and can be blocked with added $\mathrm{Ba}^{2+}$ (Bolnick et al., 1979). We elected not to use additional drugs to block PIInm to sustain larval health and survival. Routinely, ERG recordings were stable over 45 to $60 \mathrm{~min}$ at room temperature.

ERG signals in intact eyes were recorded with a limited bandpass $(0.1$ to $300 \mathrm{~Hz})$ to minimize instability due to a drifting baseline. Excluding the DC component distorts the recorded response to light steps. Whereas in a DC recording the response of cones to a light step reaches an initial peak and then sags over the following second to a lower, nearly steady value (Baylor et al., 1974), in the AC-recorded ERG cone mass receptor potential, the response appears only as a transient voltage at the onset and offset of the light step (see below). On the other hand, the cone response to a flash is transient and not significantly distorted in the AC-recorded mass receptor potential. The absolute amplitude of the mass receptor potential varied from animal to animal [maximum peak response, $326 \pm 157 \mu \mathrm{V}( \pm \mathrm{SD})$; $N=84$ ] and is not informative because it almost certainly reflects variance in the position of the recording electrodes with respect to the retinal local field potential.

\section{Comparative genomics}

We discovered CNG-modulin in a screen of striped bass retinal cDNA (GenBank accession number FJ11702; Rebrik et al., 2012), but the bass genome has not been sequenced. Among those fish whose genome has been sequenced, the stickleback (Gasterosteus aculaetus) is the nearest evolutionary relative of the striped bass (Near et al., 2012).

Protein sequence databases assembled from transcripts of available fish genomic sequences identify EML1 (echinoderm microtubuleassociated protein-like) as well aligned with CNG-modulin. Following convention, protein transcripts are denoted in regular text, and their coding genes are in italics. Also, we use lowercase italics, by convention denoting a zebrafish gene, even when we refer to the same gene in other vertebrate species. EML1 is the product of the emll gene and a member of the ancient Echinoderm microtubule-associated protein (EMAP) protein family. Emll is present in the genome of every vertebrate species 


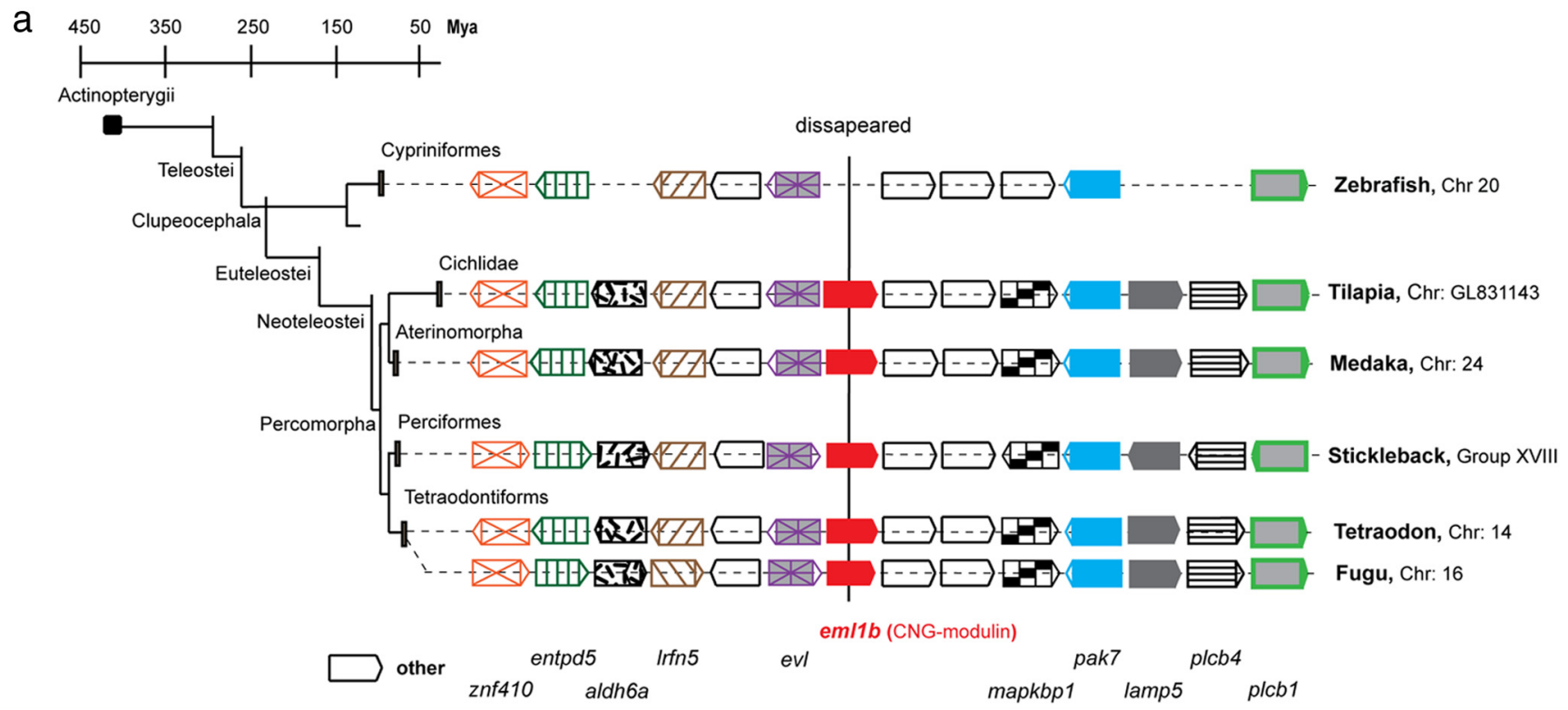

b
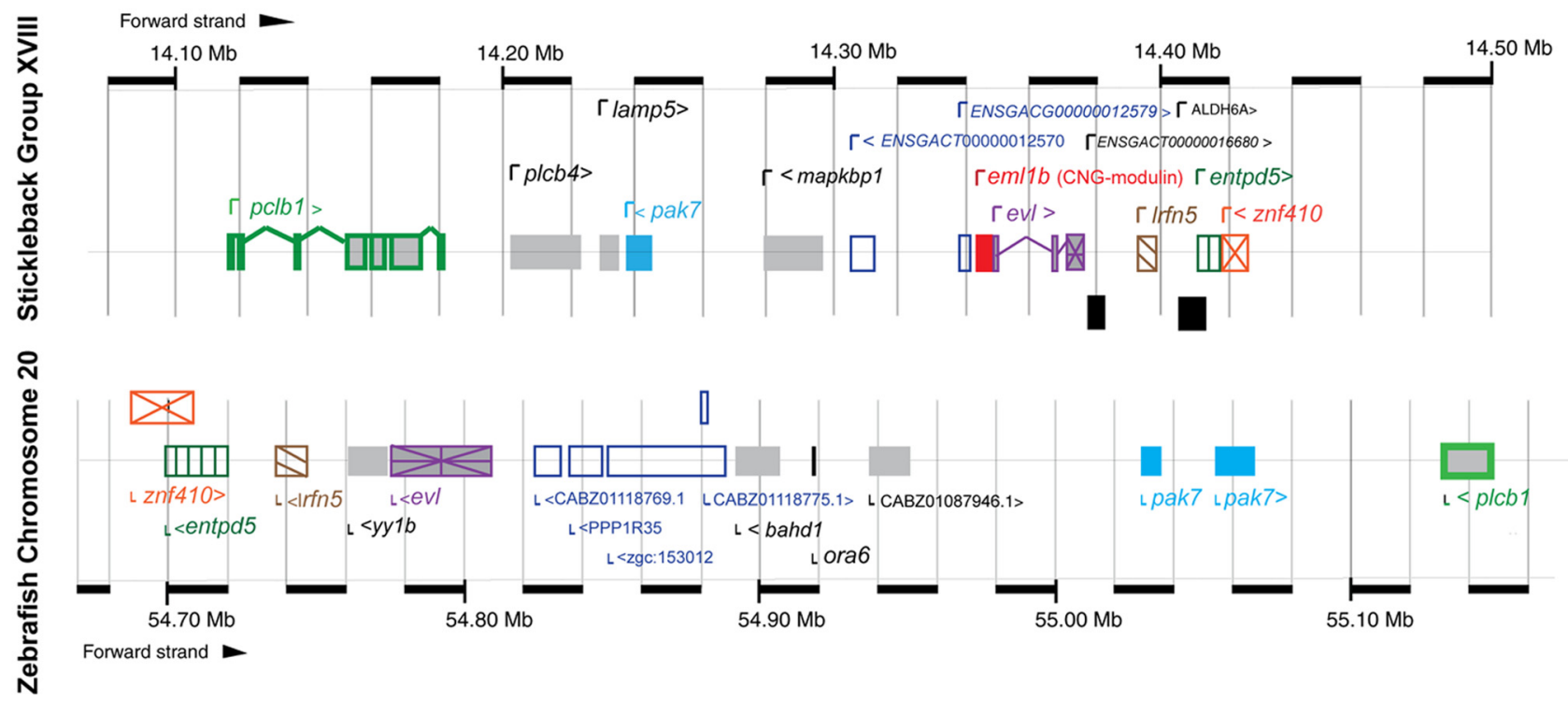

Figure 3. a, Schematic representation of genetic synteny surrounding em/1b (CNG-modulin) in the chromosome of various fish species, as labeled. The representation does not reflect the actual physical distance between the genes, just their spatial layout. To address chromosomal inversion, an arrowhead is used to indicate the gene's transcription orientation (www.genomicus.com). The chromosomal location of the gene synteny is listed next to the species name. The fish phylogeny and approximate time calibration (millions of years ago) are redrawn from the study by Near et al., (2012). Em/1 synteny is strongly conserved. $\boldsymbol{b}$, Detailed genetic architecture of selected regions in stickleback and zebrafish chromosomes. The stickleback region is in group XVIII, starting at base pair $14.08 \mathrm{Mb}$. The zebrafish region is in chromosome 20, starting at base pair $54.67 \mathrm{Mb}$. The stickleback chromosomal region includes em/1b (red box) and its genetic synteny. The zebrafish region is constituted by a gene synteny generally similar to that in stickleback (orthologue genes are color coded), but the em/16 has disappeared.

sequenced to date, as well as in the invertebrate Ciona intestinalis. EPL-1, another member of the same protein family, is found in Caenorhabditis elegans and Drosphila.

The quality of the alignment of comparable protein sequences is evaluated by a statistic value named E ("expect"). The lower the E value, or the closer it is to zero, the more "significantly related" the aligned sequences. For example, aligning bass CNG-modulin with itself scores $\mathrm{E} \sim \mathrm{e}-151$. Among all fish, and depending on species, the alignment of CNG-modulin and EML1 ranges in E values between $\sim \mathrm{e}-10$ and $\sim \mathrm{e}-29$. However, all teleost fish, except zebrafish, also show a second protein that aligns with CNGmodulin with even lower E values than EML1, between $\sim \mathrm{e}-100$ and $\sim \mathrm{e}-147$, depending on the species. This second protein is absent in zebrafish and also in other fish evolutionary ancestral to zebrafish, such as the spotted gar, a rayfin fish, and the coelencath, a lobefin fish. As we explain below, this second protein is the authentic bass CNG-modulin that evolved as a gene duplicate of eml1 after the teleost gene duplication. CNG-modulin should now more properly be referred to as EML1b.

Ambiguity in protein sequence alignment is resolved by considering, in addition, chromosomal synteny and protein phylogenetic relationships (Jovelin et al., 2007). Figure 2 illustrates the conserved synteny of emll genes in all sequenced fish, as well as in selected species of all other vertebrate classes. The chromosomal location of eml1 is listed for each species. The gene content in the chromosomal neighborhood surrounding eml1 is essentially the same among all fish and is well conserved among other vertebrates, affirming the orthology of emll genes in these species. 
a

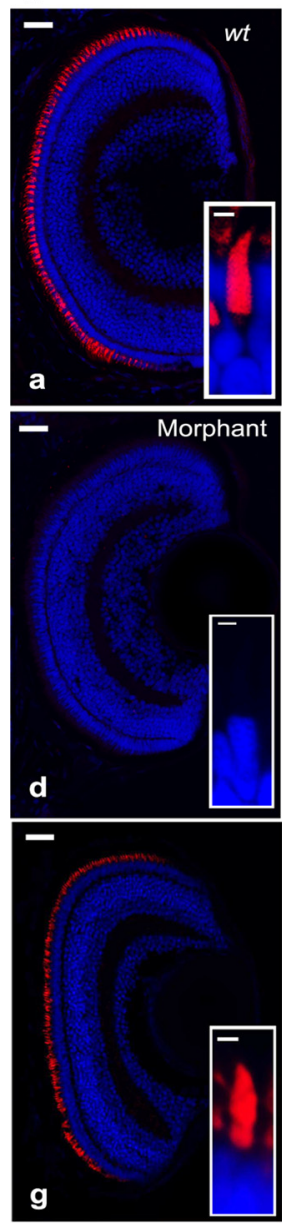

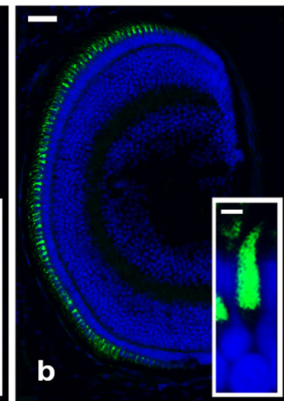
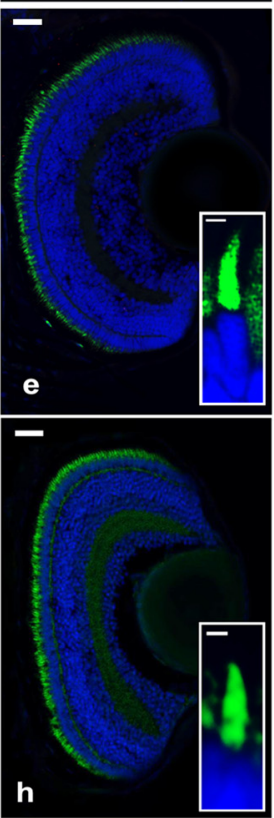
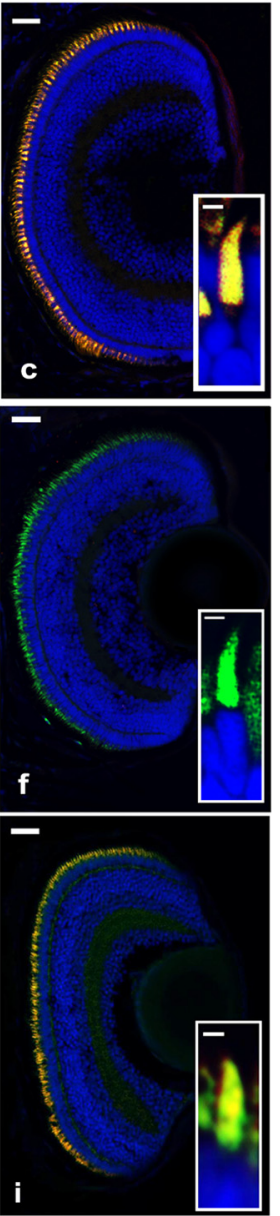

b

wt morphant

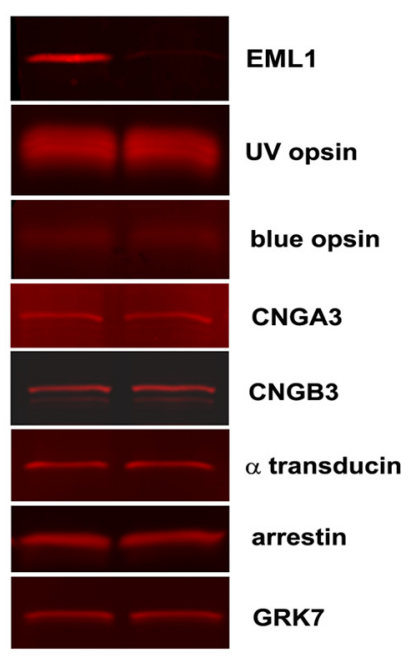

Figure 4. $\boldsymbol{a}$, Immunohistochemical assay of EML1 expression in retinal sections. Top row, Wild-type larvae $(\boldsymbol{a}-\boldsymbol{c})$. Middle row, Morphant larvae injected with anti-EML1 morpholino (d-f). Bottom row, Control larvae injected with M0-control $(\boldsymbol{g}-\boldsymbol{i})$. In each panel, the inset shows a high-magnification image of an individual cone photoreceptor. Anti-EML1 antibody is labeled in red ( $\boldsymbol{a}$, $\boldsymbol{d}, \boldsymbol{g}$ ). PNA lectin is labeled in green $(\boldsymbol{b}, \boldsymbol{e}, \boldsymbol{h}) . \boldsymbol{c}, \boldsymbol{f}, \boldsymbol{i}$, Superpositions of the images to the left, respectively. EML1 is not detectable in morphant cones, but its expression is indistinguishable in wt and M0-control larvae. Scale bars: $\boldsymbol{a}-\boldsymbol{i}, 20 \mu \mathrm{m}$; insets, $1 \mu \mathrm{m}$. $\boldsymbol{b}$, Western blots of proteins in wt and morphant eye lysates containing $5 \mu \mathrm{g}$ of total protein. Images of specific protein bands labeled with fluorescent secondary antibodies. The ratios of protein level in morphant over wild-type larvae are as follows (computed from the absolute intensity of the fluorescence images): EML1, 0.048; UV opsin, 1.02 \pm 0.08 ; blue opsin, $1.01 \pm 0.01$; cone CNG channel $\alpha$ subunit (CNGA3), $0.96 \pm 0.02$; cone CNG channel $\beta$ subunit (CNGB3), $0.96 \pm 0.06$; cone $\alpha$ transducin (G $\alpha$ t2), $0.96 \pm 0.08$; cone arrestin, $0.97 \pm 0.09$; cone opsin kinase (GRK7), $0.98 \pm 0.05$.

Figure 3 illustrates conserved syntenies surrounding eml1b. The chromosomal location of this gene is listed for each species, and it is different from that of eml1. Eml1b and the bass CNG-modulin gene are co-orthologues: the amino acid sequence of the EML1b protein across species is between 67 and $76 \%$ identical to bass CNG-modulin, and the emllb synteny is highly conserved across the species where it is found.

The model of gene evolution referred to as the duplication-degeneration-complementation model (Force et al., 1999) well explains the genomic findings. The ancient emll gene is the common ancestral gene to all vertebrate emll-related genes. The teleost gene duplication event generated two duplicates: eml1a and eml1b. In zebrafish, eml1a survived, but eml1b disappeared. Disappearance of duplicate genes is the most frequent event in the course of the evolution (Watterson, 1983; Li and Noll, 1994) and is the expected finding. Duplicate genes may survive because of subfunctionalization, a change that involves the expression of the surviving duplicate in a specific tissue, cell lineage, developmental stage, or individual functional domains within the gene's protein coding sequence.

Analysis of chromosomal conserved synteny demonstrates both the disappearance of emllb in zebrafish and its preservation and identity in all other teleost. Searching the zebrafish genome for a syntenic structure homologous to that surrounding eml1b in all other teleost fish uncovers comparable synteny in chromosome 20 (emlla is in chromosome 17). Zebrafish chromosomes 17 and 20 have long been known to be largely co-orthologous chromosomes from the TGD (Amores et al., 1998). Figure 3 illustrates the alignment of the emllb synteny in stickleback fish and the corresponding synteny in zebrafish chromosome 20 . The data show the typical eml1b synteny in stickleback fish, but in zebrafish there are several other genes between genes evl and pak, where emllb should have been, suggesting that a chromosome rearrangement may have destroyed the zebrafish $e m l 1 b$ gene. The sequence of each of the zebrafish genes in the evl to pak7 interval is known, and none is even remotely similar to eml1b. The only zebrafish gene orthologue to bass CNG-modulin is eml1 in chromosome 17.

\section{Suppression of EML1 expression in zebrafish larvae}

Expression of proteins of interest can be transiently suppressed in zebrafish larvae (transient gene knockdown) by injecting early stage embryos with morpholino oligonucleotides designed to specifically block translation (Bill et al., 2009). To suppress ex- 


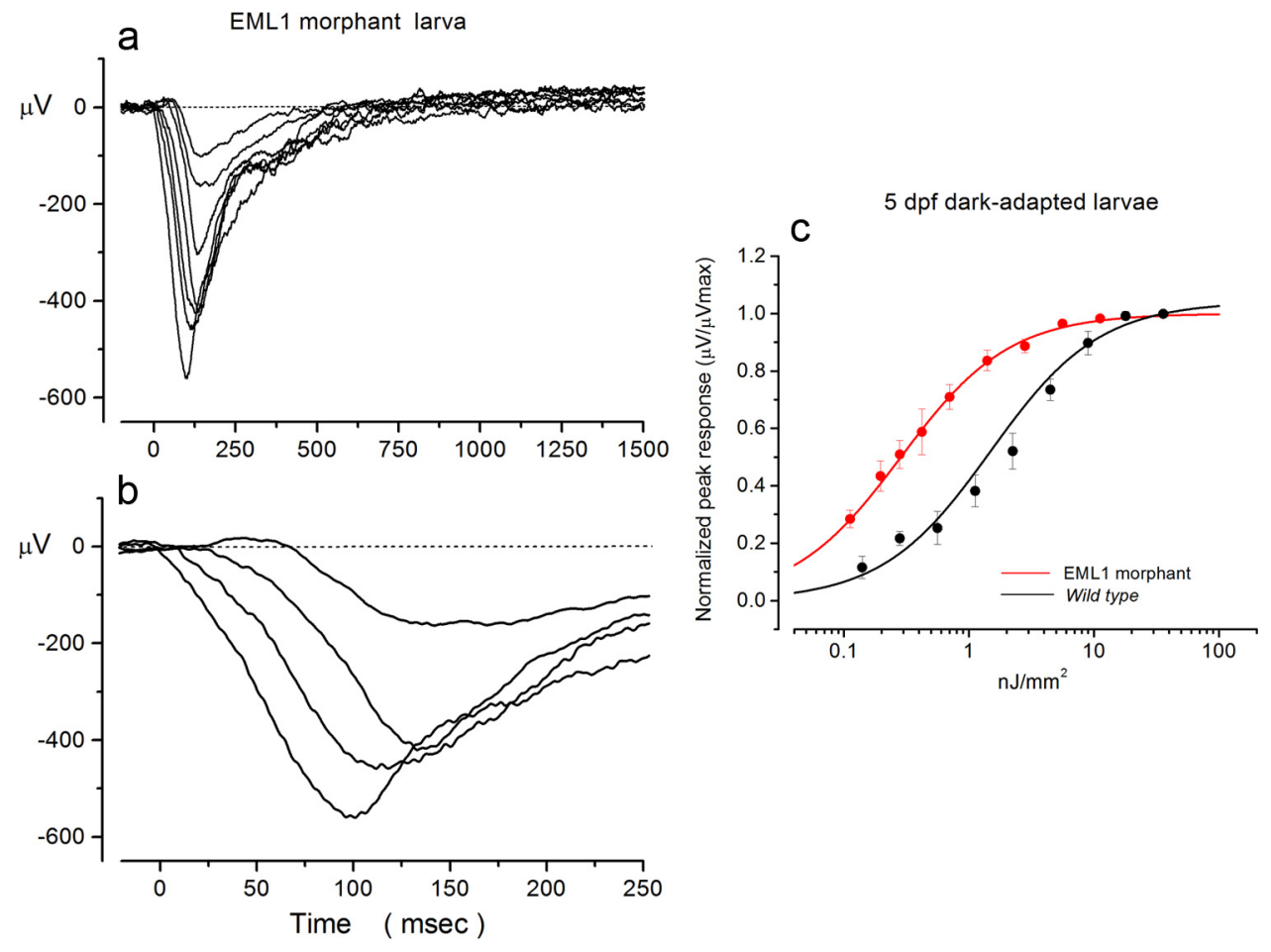

Figure 5. Flash response of dark-adapted cone photoreceptors in morphant larvae that do not express EML1. $\boldsymbol{a}$, Cone mass receptor potentials measured in five zebrafish larvae injected with M0-EML1. Responses elicited with $20 \mathrm{~ms}$ flashes of white light (LED source) of intensities $0.32,0.48,0.96,1.57,3.21$, and $6.43 \mathrm{~nJ} / \mathrm{mm}^{2} . \boldsymbol{b}$, Time-expanded view of the responses elicited by the 0.48 , $0.157,3.21$, and $6.43 \mathrm{~nJ} / \mathrm{mm}^{2}$ flashes. c, Mean ( \pm SEM) normalized peak response amplitude measured in dark-adapted wild-type (black circles) and EML1 morphant (red circles) $5 \mathrm{dpflarvae} \mathrm{under}$ identical experimental conditions using the white LED light source. The continuous lines are the Michaelis-Menten equation, $V(\phi)=V_{\max }(\phi / \phi+\sigma)$, optimally fit to the results measured in EML1 morphant larvae (red), where $\sigma=0.285 \mathrm{~nJ} / \mathrm{mm}^{2}\left(N=10\right.$; reduced $\left.\chi^{2}=0.269\right)$ and wt larvae (black), where $\sigma=1.490 \mathrm{~nJ} / \mathrm{mm} 2\left(N=10\right.$; reduced $\left.\chi^{2}=2.213\right)$. The morphant data are extremely well fit by the function, and the wt data less so. To not overinterpret our results, we elected to fit both wt and morphant results with the same function to emphasize the significant role of EML1 in the control of the photoreceptor absolute light sensitivity. In absolute terms, morphant larvae are $\sim 5.3$-fold more sensitive than wt larvae.

pression of the EML1 protein, we designed an antisense morpholino oligonucleotide (MO-EML1) that complements the 5'UTR region and the first 17 bases of the eml1 gene coding sequence in chromosome 17 (see Materials and Methods).

Injection of MO-EML1 successfully blocked detectable EML1 expression in 5 and $6 \mathrm{dpf}$ larvae. Figure 4 presents images of histological sections of fixed retinas reacted with a specific antiEML1 antibody characterized in our previous work (Rebrik et al., 2012). The polyclonal antibody was raised against a synthetic 11-mer peptide derived from the CNG-modulin sequence, a sequence that is identical in the EML1 protein. Cone photoreceptors were identified by their specific labeling with fluorescent PNA lectin (Ishikawa et al., 1997). The histological appearance of wt cones (Figure $4 b$ ) was indistinguishable from that of morphant cones (Fig. 4e). The anti-EML1 antibody labels wt cone photoreceptors (Fig. 4a), but there was no detectable antibody label of cone photoreceptors in MO-EML1-injected larvae (morphant; Fig. 4d). The expression of EML1 in PNA-labeled wt cones, but not in morphant ones, is emphasized by superposition of the respective images (Fig. $4 c, f$ ).

As a control, we also tested the consequence of injecting fertilized zebrafish eggs with a control morpholino oligonucleotide designed not to interfere with the expression of any known zebrafish protein (www.gene-tools.com). Immunohistochemical assay of the retina in $6 \mathrm{dpf}$ larvae injected with MO-control showed normal cone photoreceptors that expressed EML1 in a manner indistinguishable from that in wt retinas (Fig. $4 g-i$ ). Thus, the expression of EML1 and the structure of cones are unaffected by the mere injection of morpholino oligonucleotides.
Knockdown of EML1 expression does not affect the expression of other protein participants in the cone phototransduction pathway

To verify the effectiveness of MO-EML1 injection to suppress EML1 expression, we assayed protein expression with semiquantitative Western blots. Equal total protein samples of wt or morphant larvae eye lysates were separated by SDS-PAGE, blotted, and probed with specific primary antibodies, followed by a fluorescent secondary antibody. Figure 3 shows images of the fluorescent protein bands identified with specific antibodies against EML1 and other protein participants in the cone phototransduction cascade. Measurement of the intensity of the fluorescent images shows that EML1 expression in the morphant larvae was under $5 \%$ of that in wild-type larvae. In contrast, the levels of UV and blue opsin, cone $\alpha$ transducin (G $\alpha \mathrm{tc}$ ), cone opsin kinase (GRK7), cone arrestin, and the $\alpha$ and $\beta$ subunits of the cone CNG channels (CNGA3 and CNGB3) were essentially the same in morphant and wt larvae. Thus, injected MO-EML1 effectively suppresses the expression of EML1, but does not affect the expression of other proteins of the cone phototransduction cascade.

\section{The absolute light sensitivity of dark-adapted cones depends on EML1}

Larvae injected with MO-EML1 hatched normally, and at 5-6 dpf were indistinguishable in gross appearance from wt larvae, but they seemed less robust: wt larvae were usually anesthetized with $0.02 \%$ tricaine, but this dose was lethal to the morphants, which were anesthetized with $0.002 \%$ tricaine instead. The photoresponses of wt 
larvae were the same whether larvae were anesthetized with 0.02 or $0.002 \%$ tricaine. The wave shape and the time course of the rising phase of the cone mass potential are the same in wt and morphant larvae at 5 and $6 \mathrm{dpf}$ (Fig. 5).

To examine whether EML1 plays a role in the control of absolute photosensitivity in dark-adapted cones, we focused our analysis on $5 \mathrm{dpf}$ zebrafish larvae to mitigate the possible consequence of morpholino dilution. We quantify and compare data measured in morphant and wt larvae developed from the same pool of fertilized eggs, stimulated with the same white LED source, and anesthetized at the same $0.002 \%$ tricaine concentration. Also, we measured photosensitivity in wt and morphant larvae during daylight hours, and no more than $1 \mathrm{~h}$ into diurnal night time, because photosensitivity measured after several hours into diurnal darkness is significantly less than that measured during diurnal daylight (Emran et al., 2010).

The light sensitivity of dark-adapted cones was significantly higher in morphants lacking EML1 than in wt larvae (Fig. $5 c$ ). In $5 \mathrm{dpf}$ morphant larvae, the dependence of the normalized peak response amplitude on flash intensity is best described by the Michaelis-Menten equation, with $0.285 \pm 0.013 \mathrm{~nJ} / \mathrm{mm}^{2}(N=$ 10) as the intensity necessary to reach a half-maximum response. Using the same function to fit the data measured in wt larvae, the intensity necessary to reach a half-maximum response was $1.490 \pm 0.21$ $\mathrm{nJ} / \mathrm{mm}^{2}(N=10)$. The difference between these values is statistically significant (two-tailed, unpaired Student's $t$ test, $\left.p<10^{-5}\right)$. Although the dependence on light intensity in wt larvae is better fit with an exponential saturation function, comparing results fit with the same function demonstrates that morphant larvae are, on average, $\sim 5$.3-fold more light sensitive than wt larvae.

Time course and extent of relative sensitivity recovery in wild-type cones under continuous illumination

In the dark, cones respond to dim flashes that deliver 5 to 10 photons of the appropriate color, and the response to a dim light step is generated by the sum of individual responses (Naarendorp et al., 2010; Korenbrot, 2012b). As the mean background intensity increases, the intensity threshold at which a flash superimposed on that background generates a response also increases, as does the speed of the response (Soo et al., 2008), a phenomenon known as light adaptation (for review, see Perlman and Normann, 1998). In the response to a bright light step, adaptation is manifested in a sag from an initial $\log$ of background intensity.
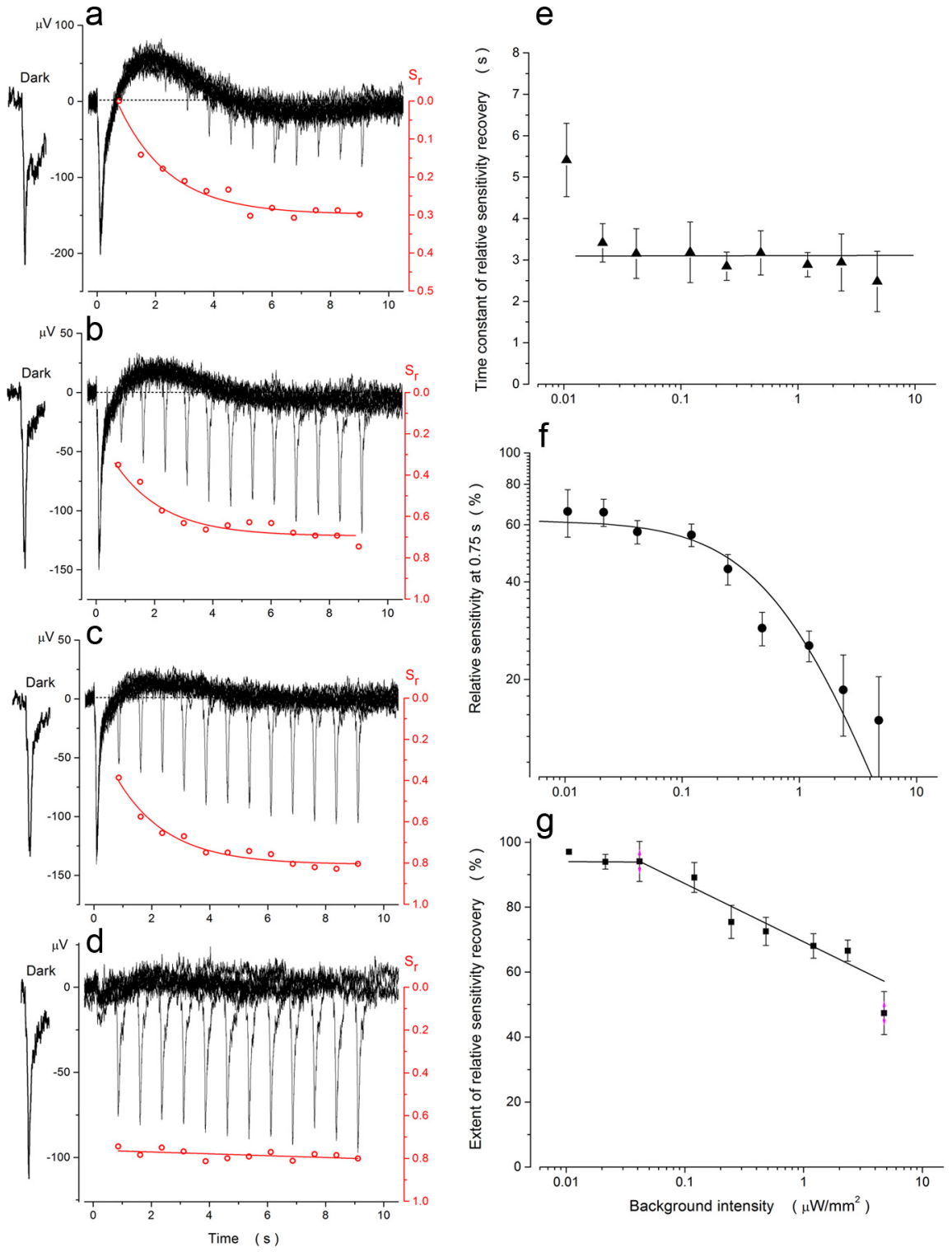

Figure 6. Recovery of cone photoreceptor light sensitivity in wild-type larvae under continuous illumination. $\boldsymbol{a}-\boldsymbol{d}$, Cone mass receptor potentials all recorded in the same wild-type $6 \mathrm{dpflarva.} \mathrm{Steps} \mathrm{of} \mathrm{constant} \mathrm{intensity,} 11.6 \mathrm{~s}$ in duration, were repeatedly presented, and one flash of fixed intensity superimposed on each step. In each successive step, the interval between step onset and flash delivery was incremented by $0.75 \mathrm{~s}$. In all panels, the fixed 20 ms test flash stimulus was white light (Xe source), $84.8 \mathrm{~nJ} / \mathrm{mm}^{2}$ in intensity. Steps were white light (W-halide source) of the following intensities (in $\mu \mathrm{W} / \mathrm{mm}^{2}$ ): $4.57(\boldsymbol{a}), 0.467(\boldsymbol{b}), 0.238$ (c), and 0.005 (d). Shown on the far left of each panel is the flash response measured in the dark-adapted state at the end of each trial of repeated steps. In each panel, the relative photosensitivity, $S_{r}=V / V_{d}$ at each time point is shown as an open red circle (red axis on the right). Continuous red lines are the exponential function $S_{r}(t)={ }^{\text {init }} S_{r}+\left({ }^{\text {fin }} S_{r}-{ }^{\text {init }} S_{r}\right)\left[1-\exp \left(-t / \tau_{s}\right)\right]$ optimally fit to the circles, with $t=0$ at the time of step onset. For the data shown in $\boldsymbol{a}^{\text {init }}{ }_{r}=0 \%, \Delta S_{r}=29.8 \%$, and $\tau_{S}=1.75 \mathrm{~s}$; in $\boldsymbol{b},{ }^{\text {init }} S_{r}=27.5 \%, \Delta S_{r}=42 \%$, and $\tau_{S}=1.68 \mathrm{~s}$; in $\boldsymbol{c}_{\text {, }}^{\text {init }} S_{r}=34 \%, \Delta S_{r}=$ $46.6 \%$, and $\tau_{s}=1.74$; in $\boldsymbol{d},{ }^{\text {init }} S_{r}=76.5 \%$, and $\Delta S_{r}=0.35 \% / s$ (straight line). $\boldsymbol{e}$, Dependence of the exponential time constant of sensitivity recovery, $\tau_{s,}$ on background intensity. Symbols (filled triangles) are the average ( \pm SEM) of measurements in 15 different larvae. At each background intensity tested, data are the mean of 3 to 15 individual measurements. The sensitivity recovery time constant was essentially independent of background intensity in the range between 0.02 and $5.0 \mu \mathrm{W} / \mathrm{mm}^{2}$, and its global mean value was $3.12 \pm$ $1.53 \mathrm{~s}( \pm \mathrm{SD} ; \mathrm{N}=80) . \mathbf{f}$, Dependence of relative sensitivity 0.75 s after step onset, ${ }^{\text {init }} \mathrm{S}_{r}$, on background intensity. Symbols (filled circles) are the average ( \pm SEM) measured in 4 to 18 larvae, 5-6 dpf. Sensitivity decreases with background intensity, as described by the WeberFechner law, the continuous line fit to the experimental data, $S_{r}(\phi)=\left(1+\phi / \phi_{b}\right)^{-1} \cdot \phi_{b}$, the intensity that reduces relative sensitivity by half, is $0.8 \mu \mathrm{W} / \mathrm{mm}^{2} . \boldsymbol{g}$, Dependence of the extent of relative sensitivity recovery, ${ }^{\text {init }}{ }_{r}+\Delta S_{r}$ on background intensity. Symbols (filled squares) are the average ( \pm SEM) measured in 4 to 18 larvae, 5-6 dpf. The extent of relative sensitivity recovery decreased linearly with the

peak to a lower, steady amplitude (Baylor and Hodgkin, 1974; Baylor et al., 1974; Normann and Werblin, 1974). The sag from peak to steady amplitude is complete within $\sim 1$ s at room temperature (Baylor et al., 1974; Soo et al., 2008). 

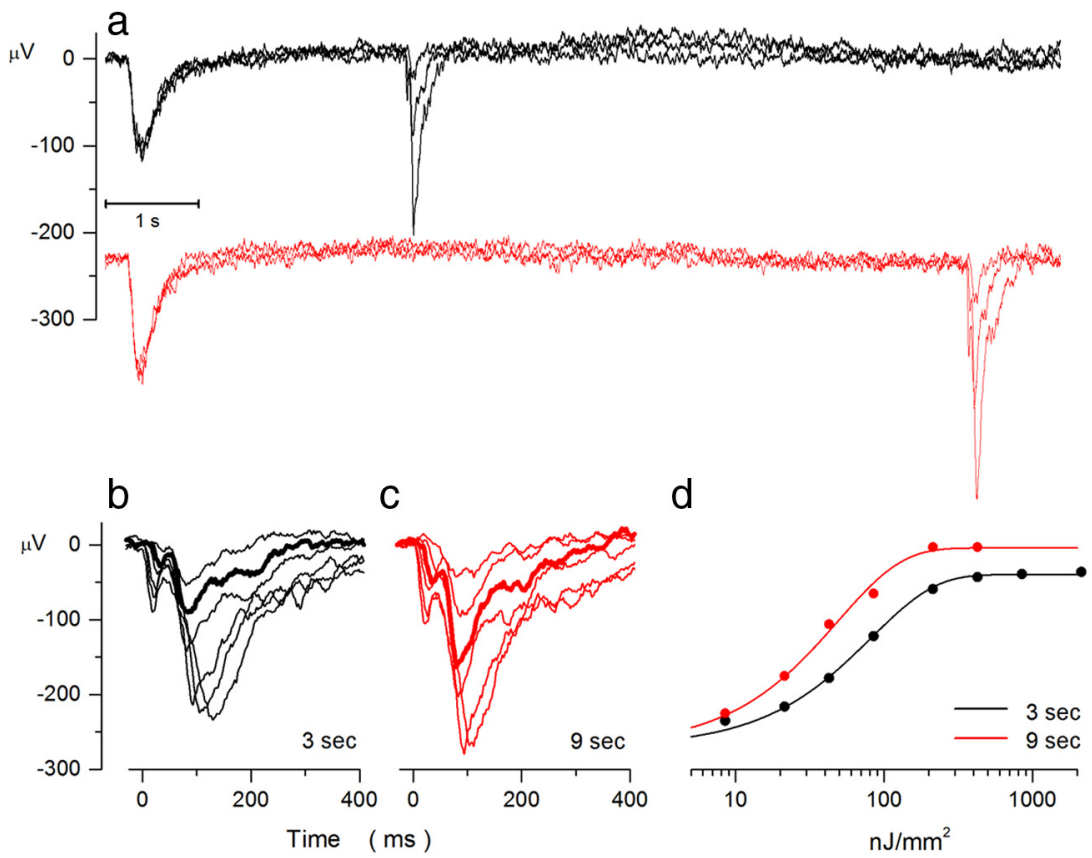

e
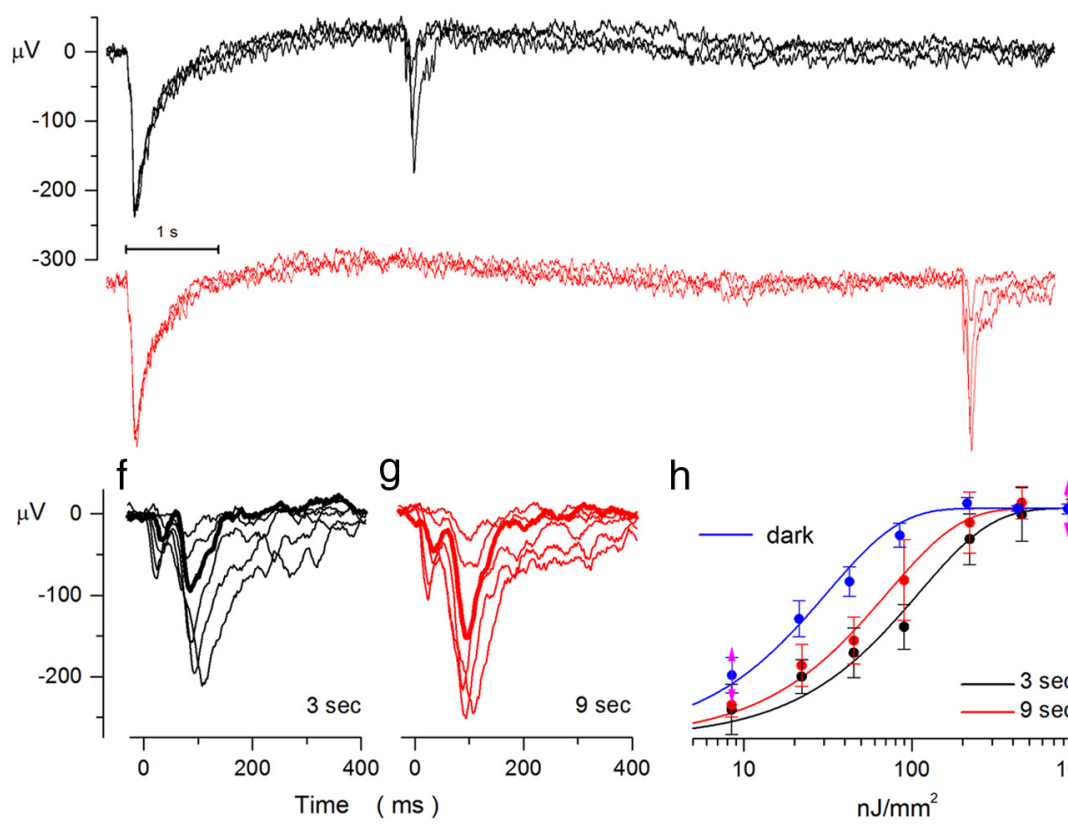

h

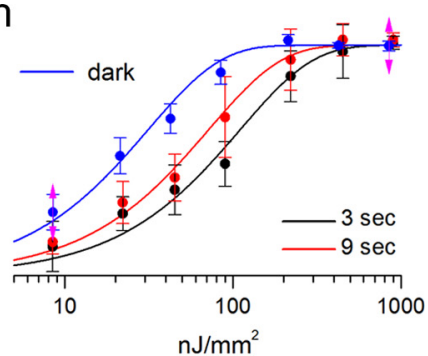

Figure 7. Recovery of absolute light sensitivity in wt zebrafish cones under continuous illumination. Cone mass receptor potentials all measured in the same wild-type, 6 dpf larva. $\boldsymbol{a}$, White light steps of $11.6 \mathrm{~s}$ duration and $0.126 \mu \mathrm{W} / \mathrm{mm}^{2}$ intensity (W-halide source) were repeatedly presented, and single flashes superimposed on each step. Flashes of increasing intensity were delivered at either $3 \mathrm{~s}$ (black traces) or $9 \mathrm{~s}$ (red traces) after step onset. $\boldsymbol{b}$, Time-expanded view of the flash responses measured at 3 sin response to 20 ms flashes of white light (Xenon) of the following intensities (in $\mathrm{nJ} / \mathrm{mm}^{2}$ ): 21.3, 42.5, 84.8, 213.2, 425.3, and 848.6. c, Time-expanded view of the flash responses measured at $9 \mathrm{~s}$ in response to $20 \mathrm{~ms}$ flashes of white light (Xenon) of the following intensities (in $\mathrm{n} / \mathrm{mm}^{2}$ ): 8.5, 21.3, 42.5, 84.8, 213.2, and 425.3. Thicker traces are responses elicited by the same intensity flash $\left(42.5 \mathrm{~nJ} / \mathrm{mm}^{2}\right) . d$, Peak amplitude of the response to the test flashes at $3 \mathrm{~s}$ (black) or $9 \mathrm{~s}$ (red) as a function of flash intensity. The continuous line is the exponential saturation function $V(\phi)=$ $V_{\max }[1-\exp (-k \phi)]$ best fit to the experimental data. At $3 \mathrm{~s}, V_{\max }=230 \mu V$ and $k=0.0123 \mathrm{~mm}^{2} / \mathrm{nJ}$. At $9 \mathrm{~s}, V_{\max }=266 \mu \mathrm{V}$ and $k=$ $0.020 \mathrm{~mm}^{2} / \mathrm{nJ}$.e, White light steps of $11.6 \mathrm{~s}$ duration and $0.508 \mu \mathrm{W} / \mathrm{mm}^{2}$ intensity (W-halide source). Flashes of increasing intensity were delivered at either $3 \mathrm{~s}$ (black traces) or $9 \mathrm{~s}$ (red traces) after step onset. $\boldsymbol{f}$, Time-expanded view of the flash responses measured at $3 \mathrm{~s}$ in response to $20 \mathrm{~ms}$ flashes of white light (Xenon) of the following intensities (in nJ/mm ${ }^{2}$ ): 8.5, 21.3, 42.5, 84.8, 213.2, and 425.3. $\boldsymbol{g}$, Time-expanded view of the flash responses measured at 9 s in response to $20 \mathrm{~ms}$ flashes of white light (Xenon) of the following intensities (in nJ/mm ${ }^{2}$ ): 8.5, 21.3, 42.5, 84.8, 213.2, and 425.3. Thicker traces are responses elicited by the same intensity flash $\left(42.5 \mathrm{~nJ} / \mathrm{mm}^{2}\right.$ ). $\boldsymbol{h}$, Average ( $\pm \mathrm{SD} ; N=4$ ) normalized peak amplitude of the response to test flashes in dark-adapted larvae (blue circles) or in larvae exposed to repeated steps of $0.508 \mu \mathrm{W} / \mathrm{mm}^{2}$ intensity and tested at $3 \mathrm{~s}$ (black circles) and $9 \mathrm{~s}$ (red circles) after step onset. Continuous lines are the exponential saturation functions best fit to the mean. In the dark, $k=0.029 \mathrm{~mm}^{2} / \mathrm{nJ}$; at $3 \mathrm{~s}, k=0.009 \mathrm{~mm}^{2} / \mathrm{nJ}$; and at $9 \mathrm{~s}, k=0.014$ $\mathrm{mm}^{2} / \mathrm{nJ}$.
The rapid (under $1 \mathrm{~s}$ ) loss of light sensitivity after the onset of background light arises from time-dependent changes in the function of cGMP-dependent phosphodiesterase and guanylate cyclase (Tranchina et al., 1991; Soo et al., 2008; Korenbrot, 2012b). However, under continuous illumination and over the following 15 to $20 \mathrm{~s}$, the initial rapid loss of light sensitivity reverses, and the absolute light sensitivity recovers toward its dark-adapted value, although it is always less than that in the dark. The recovery of photosensitivity in cones under continuous illumination was first shown in studies of the aspartate-isolated mass potential of frog retinas illuminated with flickering light (Owen and Sillman, 1973; Haynes and Sillman, 1986). Membrane voltage recordings of single cones in turtle demonstrate the same phenomenon with light flashes superimposed on light steps (Normann and Perlman, 1979; Burkhardt, 1994). The mechanisms of this slow sensitivity recovery were not understood previously, and were generally taken to be the same as those in the rapid adaptation, the transduction process simply requiring longer time to reach a truly stationary state. Here, we present evidence that the slow sensitivity recovery in cones under continuous illumination is a distinct feature of light adaptation and is mediated by EML1.

We characterized the sensitivity recovery of cones under continuous illumination by measuring the response to flashes superimposed on repeated light steps of constant intensity. Only one flash was delivered on top of each light step, and the interval between the step onset and flash presentation was incremented by $0.75 \mathrm{~s}$ in each successive step. In Figure $6 a-d$, we show typical results, all measured in the same zebrafish larva. Shown are the responses to flashes superimposed on background steps at three different intensities or presented in darkness at the end of the step sequence (traces on the far left). The responses to the light steps were invariant: the peak of the step response superimposed time and again, suggesting that photoreceptors had fully dark adapted between successive trials. The falling phase of the step response, however, reflects the AC bandpass of the recording amplifier (see Materials and Methods). The response to the very first superimposed flash (0.75 s after step onset) was smaller and faster than that in the dark, reflecting the loss of sensitivity and time course acceleration characteristic of early light adaptation (Soo et al., 2008; Korenbrot, 2012b). 
However, as the time interval between the step onset and flash delivery increased, the peak response to each flash increased in amplitude. The right-hand scale in Figure $6 a-d$ is the ratio of the peak response amplitude elicited by each flash over the peak response amplitude elicited in the dark $\left(S_{r}=V / V_{d}\right)$, a qualitative measure of relative sensitivity under continuous illumination. The relative sensitivity slowly increased up to a steady value reached some $15 \mathrm{~s}$ after background illumination started. We made similar observations in every larva thus tested $(N=37)$.

At all background intensities tested, relative sensitivity changed from an initial value, ${ }^{\text {init }} S_{r}$, to a final value, ${ }^{\text {fin }} S_{r}={ }^{\text {init }} S_{r}+$ $S_{r}$, with a time course well described by a single exponential function: $S_{r}(t)={ }^{\text {init }} S_{r}$ $+\Delta S_{r}\left[1-\exp \left(-t / t_{S}\right)\right]$ (Fig. $6 a-d$, red lines). The exponential time constant of recovery, $\tau_{S}$, was independent of background intensity with a mean value of $3.15 \mathrm{~s}( \pm 1.53 \mathrm{SD} ; N=25)$, except for the dimmest step intensity, where the extent of amplitude recovery was small (Fig. 6e). The relative sensitivity measured with the very first flash, $0.75 \mathrm{~s}$ after step onset, decreased linearly with increasing background intensities, a relationship described by the Weber-Fechner law (Fig. 6f). The law applies to many sensory modalities, and it states that signal threshold, $\Delta \phi$, the minimum intensity change that can be detected above a background intensity, $\phi$, depends linearly on that intensity, that is, $\Delta \phi / \phi$ is a constant. The extent of sensitivity recovery, $\Delta S_{r}$, depends on the adapting light intensities. The extent of recovery decreases with the log of background intensity (Fig. $6 g$ ).

\section{Absolute sensitivity recovery in wild- type cones under continuous illumination}

The absolute light sensitivity of rod and cone photoreceptors is typically assessed by determining the slope of the linear dependence of the flash response peak amplitude on light intensity or the flashlight intensity that generates a defined fraction of the maximum response amplitude. In the analysis of light-sensitivity recovery described above, we did not measure changes in absolute sensitivity, but rather relative changes assessed with a fixedintensity flash.

The sensitivity recovery under sustained illumination can be demonstrated in absolute as well as in relative units. We determined cone absolute photosensitivity by superimposing flashes of increasing intensity at 3 or $9 \mathrm{~s}$ after the onset of constantintensity light steps. Typical results all measured in the same wt larva at two different background step intensities are shown in Figure 7, $a$ and $e$, which also shows the families of flash responses in a time-expanded view (Fig. $7 b, c, f, g$ ). The thicker tracings in each set are responses to the same intensity flash. Regardless of background intensity, the light dependence of the peak ampli- tude at both 3 and $9 \mathrm{~s}$ was well described by an exponential saturation function $V=V_{\max }[1-\exp (-k \phi)]$ (Lamb et al., $1981)$, where $I_{\max }$ is the peak response amplitude, $\phi$ is light intensity, and $k$ is a sensitivity constant. The absolute sensitivity was higher at $9 \mathrm{~s}$ than $3 \mathrm{~s}($ Fig. $7 d, h)$. At a $0.508 \mu \mathrm{W} / \mathrm{mm}^{2}$ constant background (W-halide source), the absolute sensitivity at $9 \mathrm{~s}$ was $\sim 1.55$-fold higher than at $3 \mathrm{~s}$ (Fig. $7 h$ ).

\section{Sensitivity recovery under continuous illumination requires EML1}

Wild-type and morphant larvae studied under identical experimental conditions (LED light source) demonstrate comparable initial and rapid loss of light sensitivity upon exposure to a step of background light (Fig. 8). Notably, however, morphant cones did not exhibit sensitivity recovery under continuous illumination. In the absence of EML1, the peak amplitude of the response elicited by fixed-intensity flashes superimposed on prolonged light steps (11 s) was nearly constant, regardless of the delay with respect to step onset (Figure $8 b, c$ ). 

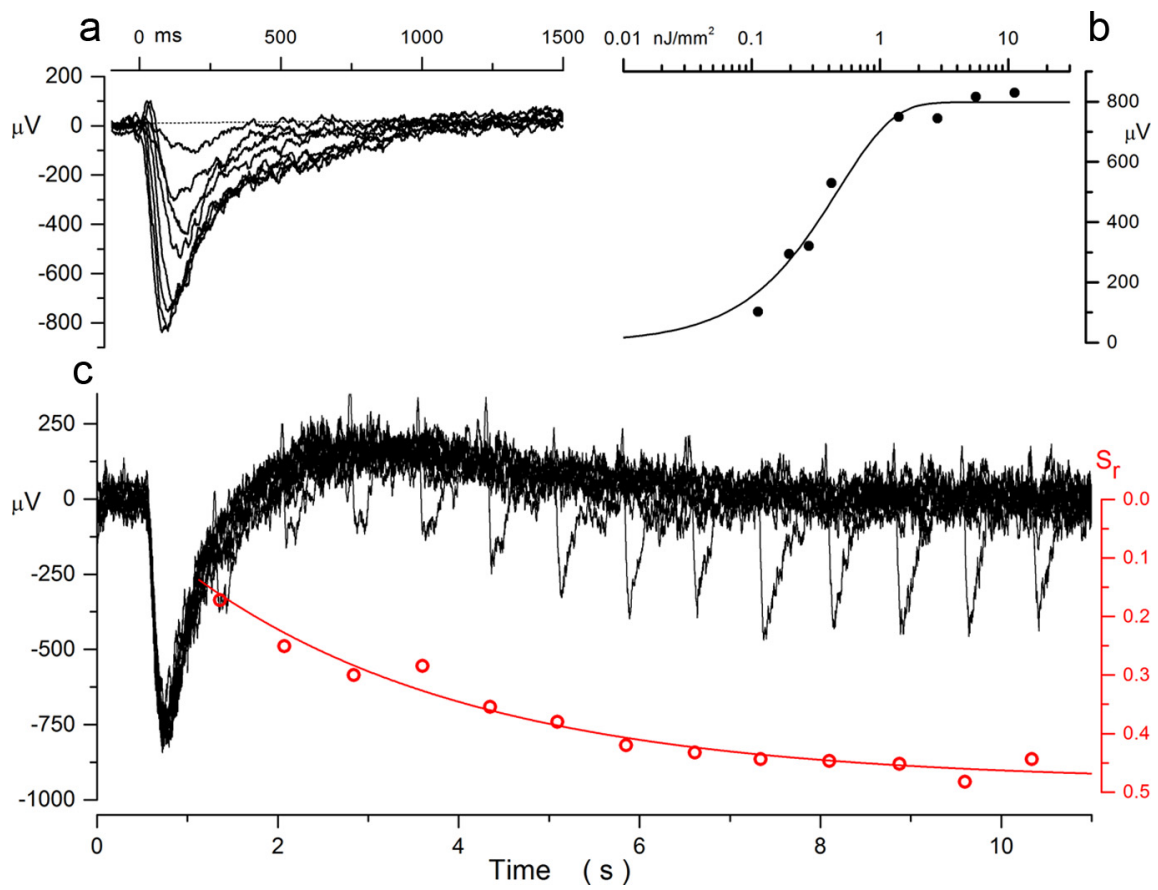

Figure 9. The cone transduction signal in wild-type larvae is unaffected by the injection of control morpholino oligonucleotides. $\boldsymbol{a}$, Response of dark-adapted larva to $20 \mathrm{~ms}$ flash (LED source) of intensities $0.11,0.20,0.42,0.7,1.4,2.8,5.6$, and $11.2 \mathrm{~nJ} / \mathrm{mm}^{2}$. Inset, A time-expanded view of the responses to $0.28,0.70,1.40,2.80$, and $5.60 \mathrm{~nJ} / \mathrm{mm}^{2}$ flashes. $\boldsymbol{b}$, Peak response amplitude as a function of light intensity (filled circles). The continuous line is the amplitude saturation function best fit to the experimental data $\left(V_{\max }=798 \mu \mathrm{V}, k=0.469 \mathrm{~mm}^{2} / \mathrm{nJ}\right)$. c, Fixed $20 \mathrm{~ms}, 1.26 \mathrm{~nJ} / \mathrm{mm}^{2}$ flashes superimposed on repeated light step $0.7 \mu \mathrm{W} / \mathrm{cm}^{2}$ in intensity. The relative photosensitivity, $S_{r}=V / V_{d \prime}$ at each time point is shown as an open red circle (scale on the right). The red line is a single exponential function, with time constant $3.1 \mathrm{~s}$, optimally fit to the relative sensitivity data points.

The time course of the change in relative light sensitivity in morphant larvae under sustained illumination was best fit by a straight line of nearly zero slope (Fig. $8 b, c)$. Mean $( \pm \mathrm{SD})$ values of the slope of this line measured at various background intensities in 13 morphants are shown in Figure 8d. On average, morphant larvae exhibited a negligible change in photosensitivity $(\sim 0.01 \% / \mathrm{s})$ over $10 \mathrm{~s}$ following light onset. In contrast, wt larvae developed from the same egg brood and studied with matched experimental parameters demonstrated an exponential recovery of relative light sensitivity (Fig. $8 a)$. The global mean time constant of relative sensitivity recovery in wt larvae over the intensity range tested was $3.37 \pm 0.85 \mathrm{~s}( \pm \mathrm{SD} ; N=$ 11 ), a value that overlaps the recovery measured using the $\mathrm{W}$-halide light source.

Control morpholino does not affect the cone photoresponse As a control for the specificity of the physiological effects of MOEML1, we studied the cone mass receptor potential of MOcontrol-injected larvae. The effects of this control morpholino, if any,would unmask changes resulting from mere egg injection or the presence of morpholino oligonucleotides in a developing animal.

We recorded cone mass receptor potentials in $6 \mathrm{dpf}$ control MOinjected larvae under the same experimental conditions as the MOEML1-injected animals. The responses elicited by flashes of varying intensity presented to a dark-adapted animal were indistinguishable from those in wt larvae (Fig. 9a). The peak amplitude of these responses increased with light intensity in a manner well described by the same exponential saturation function that describes this dependence in wt larvae (Fig. 9b). Most importantly, just as in wt larvae, control morphant larvae exhibited an exponential recovery of cone photosensitivity while under continuous il- lumination (Fig. 9c). The time constant of this recovery (2.83 to $4.34 \mathrm{~s} ; N=3$ ) was within the range of values measured in uninjected larvae. Thus, the mere injection of the morpholino oligonucleotide does not cause any detectable change in the cone photoreceptor function, affirming the specificity of the physiological effect of MO-EML1.

\section{Discussion}

We have demonstrated the function of EML1 and its participation in the recovery of sensitivity under continuous illumination in UV- and blue-sensitive zebrafish cones. Sensitivity recovery in the first tens of seconds after the onset of adapting light was first reported in ERG studies of the flicker response of several mammalian and nonmammalian species (Muller-Limmroth and Andree, 1953). Studies of flicker ERG in frog suggested that the sensitivity recovery originates in cones (Owen and Sillman, 1973; Haynes and Sillman, 1986), which was directly demonstrated in single cell studies of turtle cones under continuous illumination (Normann and Perlman, 1979; Burkhardt, 1994). In humans, the conedriven "b" wave in the ERG (Gouras and MacKay, 1989) and cone-driven psychophysical perception (Stockman et al., 2006, 2007) also exhibit slow sensitivity recovery under continuous illumination. However, the rate of this sensitivity recovery is slower than that measured in the nonmammalian photoreceptors, and it is now clear that any sensitivity recovery in the cones themselves makes only a small contribution to the sensitivity recovery measured in the ERG "b" wave (Alexander et al., 2006).

EML1 is a member of the EMAP protein family. EMAP was first cloned from highly purified sea urchin mitotic microtubules (Li and Suprenant, 1994) and is the most ancient member of the protein family that includes EML1 through EML5 in vertebrates and EPL-1 in C. elegans and Drosophila. Members of the EMAP protein family are identified on a structural, not functional, basis: they all express a hydrophobic ELP motif (PF03451; Bateman et al., 2004) and multiple copies of imperfect WD-40 repeats (PF00400; Li and Suprenant, 1994). In the absence of specific functional tests, the proteins are presumed to participate in microtubule function because of EMAP's original source, but their actual functional role is generally unknown. With respect to function, in C. elegans, EPL-1 is expressed in neurons involved in mechanoperception: touch receptor neurons and mechanosensory IL1 neurons. Reducing the expression of EPL-1 decreases the worm's sensitivity to gentle touch through unknown mechanisms (Hueston et al., 2008). In striped bass, the CNG-modulin transcript is expressed in the brain, photoreceptors, and other sensory neurons, such as the olfactory rosette and the inner ear, but also in nonneural tissues such as kidneys and gills (Rebrik et al., 2012), suggesting a role in the function of other cells in addition to photoreceptors. Cavefish live in constant darkness and have lost their eyes in the course of evolution; these fish show a specific reduction in the transcription of the genes of phototransduction proteins, including emll (Meng et al., 2013). This finding 
demonstrates a correlation in the regulation of expression the emll gene with that of other genes of phototransduction. The ligand sensitivity of CNG channels in mammalian cones is modulated by $\mathrm{Ca}^{2+}$, just as in fish (Rebrik and Korenbrot, 2004). EML1 transcripts are found in expressed sequence tag libraries derived specifically from mice and human retinas (neibank.nei. nih.gov).

The increase in photosensitivity of dark-adapted cones in the absence of EML1 was anticipated in a computational model that successfully fits photocurrents by accounting for the known biochemical and biophysical events underlying phototransduction (Korenbrot, 2012b). The change in sensitivity arises principally from the fact that in normal cones, CNG channel gating is controlled by both cGMP and $\mathrm{Ca}^{2+}$, whereas in the absence of EML1, channels will be controlled by cGMP alone. The model, however, does not anticipate sensitivity recovery under continuous illumination nor its diminution in the absence of EML1.

CNG channel modulation requires both $\mathrm{Ca}^{2+}$ and EML1 (CNG-modulin; Rebrik et al., 2012). Therefore, any timedependent effect of EML1 requires both the presence of the protein and $\mathrm{Ca}^{2+}$, and the time course of sensitivity recovery could reflect the dynamics of the protein action, the time course of changes in $\mathrm{Ca}^{2+}$ concentration, or both. The time course of sensitivity recovery in fish cones, an exponential with a time constant of $\sim 3.1 \mathrm{~s}$, cannot be explained by the dynamics of the EML1 action alone. In striped bass cones, the change in channel ligand sensitivity upon an instantaneous change in free $\mathrm{Ca}^{2+}$ is complete within hundreds of milliseconds after the sudden change in $\mathrm{Ca}^{2+}$ (Rebrik et al., 2000). On the other hand, small molecules readily diffuse in the cytoplasm from the inner (IS) to the OS with a time course comparable to that of sensitivity recovery. In striped bass cones, for example, the transfer time of 8-Br-cGMP (molecular weight, 446) from the IS to the OS is well described by a single exponential with a time constant of $\sim 3.8 \mathrm{~s}$ (Rebrik et al., 2000). Using the Stokes-Einstein equation, we can estimate that the diffusion-limited transfer time of $\mathrm{Ca}^{2+}$ (molecular weight, 40) from the inner to the outer segment cytoplasm should have an exponential time course with a time constant of $\sim 1.7 \mathrm{~s}$.

We propose that in nonmammalian cones, the slow sensitivity recovery observed upon first being exposed to steady illumination is caused by a slow rise in cytoplasmic free $\mathrm{Ca}^{2+}$ in the outer segment that follows diffusional flow of the cation from the inner to the outer segment cytoplasm. The slow rise in free $\mathrm{Ca}^{2+}$ will affect channel activity, as well as the activity of guanylate cyclase and VP kinase. This hypothesis is supported by the experimental results of Haynes and Sillman (1987), who reported that the sensitivity recovery of frog cones measured in isolated retinas under continuous flicker stimulation does not occur when $\mathrm{Ba}^{2+}(0.8$ $\mathrm{mM}$ ) is added to the extracellular medium containing low $\mathrm{Ca}^{2+}(0.4 \mathrm{~mm})$. Under these experimental conditions, lightdependent changes in cytoplasmic free $\mathrm{Ca}^{2+}$ are most likely smaller in extent than in the absence of $\mathrm{Ba}^{2+}$ because this cation permeates cone $\mathrm{CNG}$ channels nearly as well as $\mathrm{Ca}^{2+}$ itself (Haynes, 1995). When $\mathrm{Ba}^{2+}$ is present at concentrations higher than $\mathrm{Ca}^{2+}$, therefore, the fraction of the current carried by $\mathrm{Ca}^{2+}$ into the outer segment via the CNG channels will be reduced as the fraction carried by $\mathrm{Ba}^{2+}$ increases. Reduced $\mathrm{Ca}^{2+}$ influx will result in a reduced light-dependent change in the free $\mathrm{Ca}^{2+}$ concentration (Sampath et al., 1999), reducing the magnitude of the $\mathrm{Ca}^{2+}$-dependent sensitivity recovery, as postulated.
Analysis of the experimental measurement of light-dependent changes in cytoplasmic free $\mathrm{Ca}^{2+}$ in UV-sensitive zebrafish cones by Leung et al. (2007) also offer experimental support of our hypothesis. Leung et al. (2007) measured changes in free $\mathrm{Ca}^{2+}$ caused by light steps of intensity sufficient to reduce the response to a flash by $\sim 15 \%$ relative to the response in the dark-adapted state; this is comparable to the intensity range we investigated in this report (Fig. 6). They measured free $\mathrm{Ca}^{2+}$ at two single time points, 0.6 and 5 s, after the light step onset (Leung et al., 2007, their Fig. 7). Inspection of their data shows that over the intensity range in question, the free $\mathrm{Ca}^{2+}$ was lower at $0.6 \mathrm{~s}$ than at $5 \mathrm{~s}$ after light step onset; that is, step illumination reduces outer segment free $\mathrm{Ca}^{2+}$ concentration relative to that in darkness within 600 $\mathrm{ms}$ of step onset, but the $\mathrm{Ca}^{2+}$ then rises and is higher at $5 \mathrm{~s}$ than it was at $0.6 \mathrm{~s}$. This must be contrasted with the very rapid rise in $\mathrm{Ca}^{2+}$ that they observed after the onset of very bright step illumination, intensities that bleach a significant fraction of the visual pigment, and which they attributed to the lightinduced release of $\mathrm{Ca}^{2+}$ possibly form the inside surface of the plasma membrane.

Space-resolved measurements of cytoplasmic free $\mathrm{Ca}^{2+}$ in light-adapted tiger salamander rods show that activation of voltage-gated $\mathrm{Ca}^{2+}$ channels causes an immediate rapid rise in free $\mathrm{Ca}^{2+}$ in the IS cytoplasm, followed by a delayed and slower increase in the OS-free $\mathrm{Ca}^{2+}$ due to diffusion from the IS to OS (Krizaj and Copenhagen, 1998). Only future thorough measurements of the time course and light dependence of a possible slow change in cone outer segment $\mathrm{Ca}^{2+}$ will fully test our hypothesis.

\section{References}

Alexander KR, Raghuram A, Rajagopalan AS (2006) Cone phototransduction and growth of the ERG b-wave during light adaptation. Vision Res 46:3941-3948. CrossRef Medline

Altschul SF, Madden TL, Schäffer AA, Zhang J, Zhang Z, Miller W, Lipman DJ (1997) Gapped BLAST and PSI-BLAST: a new generation of protein database search programs. Nucleic Acids Res 25:3389-3402. CrossRef Medline

Amores A, Force A, Yan YL, Joly L, Amemiya C, Fritz A, Ho RK, Langeland J, Prince V, Wang YL, Westerfield M, Ekker M, Postlethwait JH (1998) Zebrafish hox clusters and vertebrate genome evolution. Science 282: 1711-1714. CrossRef Medline

Bateman A, Coin L, Durbin R, Finn RD, Hollich V, Griffiths-Jones S, Khanna A, Marshall M, Moxon S, Sonnhammer EL, Studholme DJ, Yeats C, Eddy SR (2004) The Pfam protein families database. Nucleic Acids Res 32: D138-D141. CrossRef Medline

Baylor DA, Hodgkin AL (1974) Changes in time scale and sensitivity in turtle photoreceptors. J Physiol 242:729-758. Medline

Baylor DA, Hodgkin AL, Lamb TD (1974) The electrical response of turtle cones to flashes and steps of light. J Physiol 242:685-727. Medline

Bevington PR (1969) Data reduction and error analysis for the physical sciences. New York: McGraw-Hill.

Bill BR, Petzold AM, Clark KJ, Schimmenti LA, Ekker SC (2009) A primer for morpholino use in zebrafish. Zebrafish 6:69-77. CrossRef Medline

Bilotta J, Saszik S, Sutherland SE (2001) Rod contributions to the electroretinogram of the dark-adapted developing zebrafish. Dev Dyn 222:564570. CrossRef Medline

Bolnick DA, Walter AE, Sillman AJ (1979) Barium suppresses slow PIII in perfused bullfrog retina. Vision Res 19:1117-1119. CrossRef Medline

Branchek T (1984) The development of photoreceptors in the zebrafish, Brachydanio rerio. II. Function. J Comp Neurol 224:116-122. CrossRef Medline

Burkhardt DA (1994) Light adaptation and photopigment bleaching in cone photoreceptors in situ in the retina of the turtle. J Neurosci 14:10911105. Medline

Cameron DA (2002) Mapping absorbance spectra, cone fractions, and neuronal mechanisms to photopic spectral sensitivity in the zebrafish. Vis Neurosci 19:365-372. Medline 
Catchen JM, Conery JS, Postlethwait JH (2009) Automated identification of conserved synteny after whole-genome duplication. Genome Res 19: 1497-1505. CrossRef Medline

Catchen JM, Braasch I, Postlethwait JH (2011) Conserved synteny and the zebrafish genome. Methods Cell Biol 104:259-285. CrossRef Medline

Dahlem TJ, Hoshijima K, Jurynec MJ, Gunther D, Starker CG, Locke AS, Weis AM, Voytas DF, Grunwald DJ (2012) Simple methods for generating and detecting locus-specific mutations induced with TALENs in the zebrafish genome. PLoS Genet 8:e1002861. CrossRef Medline

Dehal P, Boore JL (2005) Two rounds of whole genome duplication in the ancestral vertebrate. PLoS Biol 3:e314. CrossRef Medline

Dizhoor AM, Lowe DG, Olshevskaya EV, Laura RP, Hurley JB (1994) The human photoreceptor membrane guanylyl cyclase, RetGC, is present in outer segments and is regulated by calcium and a soluble activator. Neuron 12:1345-1352. CrossRef Medline

Emran F, Rihel J, Adolph AR, Dowling JE (2010) Zebrafish larvae lose vision at night. Proc Natl Acad Sci U S A 107:6034-6039. CrossRef Medline

Force A, Lynch M, Pickett FB, Amores A, Yan YL, Postlethwait J (1999) Preservation of duplicate genes by complementary, degenerative mutations. Genetics 151:1531-1545. Medline

Gouras P, MacKay CJ (1989) Growth in amplitude of the human cone electroretinogram with light adaptation. Invest Ophthalmol Vis Sci 30:625630. Medline

Haynes LW (1995) Permeation and block by internal and external divalent cations of the catfish cone photoreceptor cGMP-gated channel. J Gen Physiol 106:507-523. CrossRef Medline

Haynes LW, Sillman AJ (1986) Sensitivity and response kinetics alter during suppression-recovery in cone photoreceptors. Experientia 42:1225-1226. CrossRef Medline

Haynes LW, Sillman AJ (1987) The effects of barium on the suppressionrecovery phenomenon in the aspartate isolated mass receptor response. Curr Eye Res 6:545-554. CrossRef Medline

Hueston JL, Herren GP, Cueva JG, Buechner M, Lundquist EA, Goodman MB, Suprenant KA (2008) The C. elegans EMAP-like protein, ELP-1 is required for touch sensation and associates with microtubules and adhesion complexes. BMC Dev Biol 8:110. CrossRef Medline

Ishikawa M, Hashimoto Y, Tonosaki A, Sakuragi S (1997) Preference of peanut agglutinin labeling for long-wavelength-sensitive cone photoreceptors in the dace retina. Vision Res 37:383-387. CrossRef Medline

Jovelin R, He X, Amores A, Yan YL, Shi R, Qin B, Roe B, Cresko WA, Postlethwait JH (2007) Duplication and divergence of fgf8 functions in teleost development and evolution. J Exp Zool B Mol Dev Evol 308:730-743. Medline

Kawamura S, Kuwata O, Yamada M, Matsuda S, Hisatomi O, Tokunaga F (1996) Photoreceptor protein s26, a cone homologue of S-modulin in frog retina. J Biol Chem 271:21359-21364. CrossRef Medline

Korenbrot JI (2012a) Speed, sensitivity, and stability of the light response in rod and cone photoreceptors: facts and models. Prog Retin Eye Res 31: 442-466. CrossRef Medline

Korenbrot JI (2012b) Speed, adaptation, and stability of the response to light in cone photoreceptors: the functional role of Ca-dependent modulation of ligand sensitivity in cGMP-gated ion channels. J Gen Physiol 139:31-56. CrossRef Medline

Krizaj D, Copenhagen DR (1998) Compartmentalization of calcium extrusion mechanisms in the outer and inner segments of photoreceptors. Neuron 21:249-256. CrossRef Medline

Lamb TD, McNaughton PA, Yau KW (1981) Spatial spread of activation and background desensitization in toad rod outer segments. J Physiol 319:463-496. Medline

Leung YT, Fain GL, Matthews HR (2007) Simultaneous measurement of current and calcium in the ultraviolet-sensitive cones of zebrafish. J Physiol 579:15-27. CrossRef Medline

Li Q, Suprenant KA (1994) Molecular characterization of the 77-kDa echinoderm microtubule-associated protein. Homology to the betatransducin family. J Biol Chem 269:31777-31784. Medline

Li X, Noll M (1994) Evolution of distinct developmental functions of three Drosophila genes by acquisition of different cis-regulatory regions. Nature 367:83-87. CrossRef Medline

Lobanova ES, Herrmann R, Finkelstein S, Reidel B, Skiba NP, Deng WT, Jo R, Weiss ER, Hauswirth WW, Arshavsky VY (2010) Mechanistic basis for the failure of cone transducin to translocate: why cones are never blinded by light. J Neurosci 30:6815-6824. CrossRef Medline
Louis A, Muffato M, Roest Crollius H (2013) Genomicus: five genome browsers for comparative genomics in eukaryota. Nucleic Acids Res 41: D700-705. CrossRef Medline

Meng F, Braasch I, Phillips JB, Lin X, Titus T, Zhang C, Postlethwait JH (2013) Evolution of the eye transcriptome under constant darkness in Sinocyclocheilus cavefish. Mol Biol Evol 30:1527-1543. CrossRef Medline

Muller-Limmroth HW, Andree G (1953) [Effect of flicker light on electroretinogram]. Pflugers Arch 257:216-233. CrossRef Medline

Naarendorp F, Esdaille TM, Banden SM, Andrews-Labenski J, Gross OP, Pugh EN Jr (2010) Dark light, rod saturation, and the absolute and incremental sensitivity of mouse cone vision. J Neurosci 30:12495-12507. CrossRef Medline

Near TJ, Eytan RI, Dornburg A, Kuhn KL, Moore JA, Davis MP, Wainwright PC, Friedman M, Smith WL (2012) Resolution of ray-finned fish phylogeny and timing of diversification. Proc Natl Acad Sci U S A 109: 13698-13703. CrossRef Medline

Nelson RF, Singla N (2009) A spectral model for signal elements isolated from zebrafish photopic electroretinogram. Vis Neurosci 26:349-363. CrossRef Medline

Normann RA, Perlman I (1979) The effects of background illumination on the photoresponses of red and green cones. J Physiol 286:491-507. Medline

Normann RA, Werblin FS (1974) Control of retinal sensitivity. I. Light and dark adaptation of vertebrate rods and cones. J Gen Physiol 63:37-61. CrossRef Medline

Osawa S, Jo R, Weiss ER (2008) Phosphorylation of GRK7 by PKA in cone photoreceptor cells is regulated by light. J Neurochem 107:1314-1324. CrossRef Medline

Owen WG, Sillman AJ (1973) The suppression-recovery effect in the frog photoreceptor. Vision Res 13:2591-2594. CrossRef Medline

Palczewski K, Subbaraya I, Gorczyca WA, Helekar BS, Ruiz CC, Ohguro H, Huang J, Zhao X, Crabb JW, Johnson RS, Walsh KA, Gray-Keller MP, Detwiler PB, Baehr W (1994) Molecular cloning and characterization of retinal photoreceptor guanylyl cyclase-activating protein. Neuron 13 : 395-404. CrossRef Medline

Perlman I, Normann RA (1998) Light adaptation and sensitivity controlling mechanisms in vertebrate photoreceptors. Prog Retin Eye Res 17:523563. CrossRef Medline

Postlethwait JH (2007) The zebrafish genome in context: ohnologs gone missing. J Exp Zool B Mol Dev Evol 308:563-577. Medline

Postlethwait JH, Yan YL, Gates MA, Horne S, Amores A, Brownlie A, Donovan A, Egan ES, Force A, Gong Z, Goutel C, Fritz A, Kelsh R, Knapik E, Liao E, Paw B, Ransom D, Singer A, Thomson M, Abduljabbar TS, et al. (1998) Vertebrate genome evolution and the zebrafish gene map. Nat Genet 18:345-349. CrossRef Medline

Raymond PA, Barthel LK, Curran GA (1995) Developmental patterning of rod and cone photoreceptors in embryonic zebrafish. J Comp Neurol 359:537-550. CrossRef Medline

Rebrik TI, Korenbrot JI (1998) In intact cone photoreceptors, a Ca2+dependent, diffusible factor modulates the cGMP-gated ion channels differently than in rods. J Gen Physiol 112:537-548. CrossRef Medline

Rebrik TI, Korenbrot JI (2004) In intact mammalian photoreceptors, $\mathrm{Ca} 2+$-dependent modulation of cGMP-gated ion channels is detectable in cones but not in rods. J Gen Physiol 123:63-75. Medline

Rebrik TI, Kotelnikova EA, Korenbrot JI (2000) Time course and $\mathrm{Ca}(2+)$ dependence of sensitivity modulation in cyclic GMP-gated currents of intact cone photoreceptors. J Gen Physiol 116:521-534. CrossRef Medline

Rebrik TI, Botchkina I, Arshavsky VY, Craft CM, Korenbrot JI (2012) CNGmodulin: a novel Ca-dependent modulator of ligand sensitivity in cone photoreceptor cGMP-gated ion channels. J Neurosci 32:3142-3153. CrossRef Medline

Renninger SL, Gesemann M, Neuhauss SC (2011) Cone arrestin confers cone vision of high temporal resolution in zebrafish larvae. Eur J Neurosci 33:658-667. CrossRef Medline

Robinson J, Schmitt EA, Dowling JE (1995) Temporal and spatial patterns of opsin gene expression in zebrafish (Danio rerio). Vis Neurosci 12:895906. CrossRef Medline

Sampath AP, Matthews HR, Cornwall MC, Bandarchi J, Fain GL (1999) Light-dependent changes in outer segment free- $\mathrm{Ca}^{2+}$ concentration in salamander cone photoreceptors. J Gen Physiol 113:267-277. CrossRef Medline 
Saszik S, Bilotta J, Givin CM (1999) ERG assessment of zebrafish retinal development. Vis Neurosci 16:881-888. Medline

Schmitt EA, Dowling JE (1999) Early retinal development in the zebrafish, Danio rerio: light and electron microscopic analyses. J Comp Neurol 404: 515-536. CrossRef Medline

Schmitt EA, Hyatt GA, Dowling JE (1999) Erratum: Temporal and spatial patterns of opsin gene expression in the zebrafish (Danio rerio): corrections with additions. Vis Neurosci 16:601-605. Medline

Soo FS, Detwiler PB, Rieke F (2008) Light adaptation in salamander L-cone photoreceptors. J Neurosci 28:1331-1342. CrossRef Medline

Stockman A, Langendörfer M, Smithson HE, Sharpe LT (2006) Human cone light adaptation: from behavioral measurements to molecular mechanisms. J Vis 6:1194-1213. Medline

Stockman A, Langendörfer M, Sharpe LT (2007) Human short-wavelengthsensitive cone light adaptation. J Vis 7:4. CrossRef Medline
Takechi M, Hamaoka T, Kawamura S (2003) Fluorescence visualization of ultraviolet-sensitive cone photoreceptor development in living zebrafish. FEBS Lett 553:90-94. CrossRef Medline

Tranchina D, Sneyd J, Cadenas ID (1991) Light adaptation in turtle cones. Testing and analysis of a model for phototransduction. Biophys J 60:217237. CrossRef Medline

Vihtelic TS, Doro CJ, Hyde DR (1999) Cloning and characterization of six zebrafish photoreceptor opsin cDNAs and immunolocalization of their corresponding proteins. Vis Neurosci 16:571-585. Medline

Watterson GA (1983) On the time for gene silencing at duplicate loci. Genetics 105:745-766. Medline

Wong KY, Adolph AR, Dowling JE (2005) Retinal bipolar cell input mechanisms in giant danio. I. Electroretinographic analysis. J Neurophysiol 93:84-93. Medline 